\title{
A proteomic approach to identify metalloproteins and metal-binding proteins in liver from diabetic rats
}

\author{
Camila Pereira Braga ${ }^{a, *}$, José Cavalcante Souza Vieira ${ }^{\mathrm{a}}$, Ryan A. Grove ${ }^{\mathrm{b}}$, Cory H.T. Boone ${ }^{\mathrm{b}}$, \\ Aline de Lima Leite ${ }^{c}$, Marília Afonso Rabelo Buzalaf ${ }^{c}$, Ana Angélica Henrique Fernandes ${ }^{a}$, \\ Jiri Adamec ${ }^{\mathrm{b}}$, Pedro de Magalhaes Padilha ${ }^{\mathrm{a}}$
}

a Department of Chemistry and Biochemistry, Institute of Bioscience of Botucatu, São Paulo State University, Botucatu, SP, Brazil

${ }^{\mathrm{b}}$ Department of Biochemistry, University of Nebraska-Lincoln, Lincoln, NE, USA

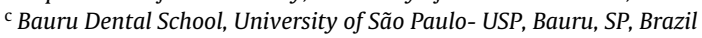

\section{A R T I C L E I N F O}

\section{Article history:}

Received 13 September 2016

Received in revised form

10 December 2016

Accepted 21 December 2016

Available online 3 January 2017

\section{Keywords:}

Electrospray ionization-tandem mass

spectrometry

Flame atomic absorption spectrometry

Graphite furnace atomic absorption

spectrometry

Metalloproteomic

Type 1 diabetes

Two-dimensional electrophoresis

\begin{abstract}
A B S T R A C T
Proteins play crucial roles in biological systems, thus studies comparing the protein pattern present in a healthy sample with an affected sample have been widely used for disease biomarker discovery. Although proteins containing metal ions constitute only a small proportion of the proteome, they are essential in a multitude of structural and functional processes. The correct association between metal ions and proteins is essential because this binding can significantly interfere with normal protein function. Employment of a metalloproteomic study of liver samples from diabetic rats permitted determination of the differential abundance of copper-, selenium-, zinc- and magnesium-associated proteins between diabetic, diabetic treatment with insulin and non-diabetic rats. Proteins were detected by ESI-MS/MS. Seventy-five different proteins were found with alterations in the metal ions of interest. The most prominent pathways affected under the diabetic model included: amino-acid metabolism and its derivates, glycogen storage, metabolism of carbohydrates, redox systems and glucose metabolism. Overall, the current methods employed yielded a greater understanding of metal binding and how type 1 diabetes and insulin treatment can modify some metal bonds in proteins, and therefore affect their mechanism of action and function.
\end{abstract}

(C) 2017 Elsevier B.V. All rights reserved.

\section{Introduction}

Type 1 diabetes mellitus (DM1) is a severe metabolic disorder and a public health concern. Clinical complications of DM1 include damage and dysfunction of multiple organs with secondary complications, such as atherosclerosis, retinopathy and renal insufficiency [1].

Although metal ions comprise a small proportion of body tissues (4\%), they are essential as structural components and in many life processes. The main roles of these metal ions can be described as structural and functional [2]. Metal ions bound to proteins and metalloproteins represent a large portion of the total protein. These ions are responsible for many metabolic processes, such as energy conversion in photosynthesis and respiration, gene regulation, substrate activation and other catalytic processes, transport and storage [3].

\footnotetext{
* Corresponding author.

E-mail addresses: braga_ca@ibb.unesp.br, braga_ca@yahoo.com.br (C.P. Braga).
}

Copper $(\mathrm{Cu})$ is an essential component of many metalloenzymes, including cytochrome oxidase, lysyl oxidase, superoxide dismutase, dopamine-ß-hydroxylase and tyrosinase [4]. Superoxide dismutase (SOD) is a metalloprotein that contains $\mathrm{Cu}$ and zinc $(\mathrm{Zn})$ that catalyzes the decomposition of the superoxide anion. Therefore, it is a component of the cellular defense system protecting against oxidative damage. $\mathrm{Cu}$ is a vital component of electron transfer reactions of SOD, underlying its antioxidant function [5].

Experimental data shows that magnesium $(\mathrm{Mg})$ is required as an important cofactor in many enzyme reactions. Importantly for DM1, Mg participates in phosphorylation reactions of glucose metabolism [6]. It is essential in almost all energy transduction systems in the glycolytic pathway and in oxidative energy metabolism, which is required for the synthesis and oxidation of fatty acids, protein synthesis, muscle contraction and ATPase activity [7]. Additionally, Mg participates in the intracellular signaling system, phosphorylation and dephosphorylation reactions that activate or inhibit a multitude of enzymes [8].

Selenium (Se) is a nonmetal, essential micronutrient for the synthesis of selenoproteins, which play an important role in the 
synthesis, metabolism and action of thyroid hormones. Furthermore, Se modifies the expression of selenoproteins, including the families of peroxidases, selenoenzymes, glutathione and thioredoxin [9]. $\mathrm{Zn}$ is a component of synthetases and transferases, including DNA and RNA, digestive enzymes, and associates with insulin. Zn also participates in metabolic pathways involving protein synthesis, carbohydrates, lipids and nucleic acids. In addition, zinc also plays a role in apoptotically driven programmed cell death [10].

Studies have reported alterations in metal ions by diabetes mellitus and suggested that the imbalance of specific elements may play an important role in normal glucose and insulin metabolism $[11,12]$. In the majority of studies, the focus is on analyzing concentrations and on the status of a single element or combinations of elements in blood, plasma or tissues; in our study, the focus is the on the integration of traditional analytical studies with inorganic and biochemical studies. For this study, we used a robust methodology to assist in understanding the variability of $\mathrm{Cu}, \mathrm{Mg}$, Se and $\mathrm{Zn}$ in diabetes and how treatment with insulin can alter this condition, providing valuable information about how $\mathrm{Cu}, \mathrm{Mg}$, Se and $\mathrm{Zn}$ are distributed with proteins, as well as the individual concentration in specific proteins, which helps to elucidate the physiological and functional aspects of biomolecules in the liver.

In this context, the present study involves the investigation $\mathrm{Cu}, \mathrm{Mg}$, Se and $\mathrm{Zn}$ found in liver samples from diabetic rats using flame atomic absorption spectrometry (FAAS) and graphite furnace atomic absorption spectrometry (GFAAS), by protein fractionation (two-dimensional gel electrophoresis, 2D-PAGE) and identification by electrospray ionization-tandem mass spectrometry (ESI-MS/MS).

\section{Material and methods}

\subsection{Animals and experimental groups}

A total of 24 Wistar male rats (Rattus norvegicus), 45 days old, were used in the experiment; these were kept in individual plastic cages with a controlled temperature and photoperiod, and they received water and a commercial diet (Purina ${ }^{\circledR}$, Labina, Campinas-SP) ad libitum throughout the experimental period. The experimental design was approved by the Ethics Committee on the Use of Animals (CEUA) at the Institute of Biosciences/São Paulo State University (UNESP), Botucatu, Brazil (protocol: CEUA436/2012). The animals were divided into three groups $(n=8)$ : C (control group): normal rats, DM1: diabetic rats and DM1 + I: diabetic rats that received insulin. Diabetes mellitus was induced with the administration of streptozotocin (STZ; $60 \mathrm{mg} /$ body weight, single dose, i.p.). Blood glucose was measured $48 \mathrm{~h}$ after the STZ administration, and animals with glycemic levels greater than $220 \mathrm{mg} \mathrm{dL}^{-1}$ were considered diabetic. The animals received insulin in the form of Humulin N100UI neutral protamine Hagedorn (NPH; Lilly ${ }^{\circledR}$ ) with an initial dose of $3 \mathrm{U} / \mathrm{animal}$; this dose was adjusted or maintained so that serum glucose levels were kept within the normal range. At the end of the 30 day experimental period, the animals were anesthetized (ketamine hydrochloride $10 \%, 0.1 \mathrm{~mL} / 100 \mathrm{~g}$ body weight, i.p.) and sacrificed by decapitation, and the liver was collected.

\subsection{Sample preparation}

Approximately $1.00 \mathrm{~g}$ of pooled sample (liver) was weighed in triplicate and ground with $2 \mathrm{~mL}$ of ultrapure water, macerated, and the protein extracts were separated from the solid portion by centrifugation at $10,000 \mathrm{~g}$ at $4{ }^{\circ} \mathrm{C}$ for $10 \mathrm{~min}$ in a refrigerated centrifuge. The protein extracts were used to quantify protein resuspension in a protein pellet with $0.50 \mathrm{~mol} \mathrm{~L}^{-1} \mathrm{NaOH}$. The total protein concentration of the liver samples was determined by the Biuret method using bovine serum albumin as the standard. Analytical calibration curves were constructed with concentrations of $10-100 \mathrm{~g} \mathrm{~L}^{-1}$ from a stock solution of albumin $\left(100 \mathrm{~g} \mathrm{~L}^{-1}\right)$. The method used $50 \mathrm{~mL}$ of sample for the standard and $2.5 \mathrm{~mL}$ of Biuret reagent, which was mixed and placed in a water bath at $32{ }^{\circ} \mathrm{C}$ for $10 \mathrm{~min}$. After $5 \mathrm{~min}$ at room temperature, absorbance readings were performed in a spectrophotometer at a wavelength of $545 \mathrm{~nm}$.

\subsection{Electrophoretic runs (2D-PAGE)}

With the standardization of the gels, the electrophoretic runs were performed using liver samples for the different experimental groups. Six gels were made for each group (pooled). Aliquots of pooled liver were diluted in a urea solution containing $7 \mathrm{~mol} \mathrm{~L}^{-1}$; $2 \mathrm{~mol} \mathrm{~L}^{-1}$ thiourea, 2\% (w/v) CHAPS (3-[(3-cholamidopropyl)dimethylammonio]-1-propanesulfonate), $0.5 \%(\mathrm{v} / \mathrm{v})$ ampholytes at a $\mathrm{pH}$ ranging from 3 to $10,0.002 \%(\mathrm{w} / \mathrm{v})$ bromophenol blue and $2.8 \mathrm{mg}$ of dithiothreitol (DTT) were added to this buffer, and the mixture was used in the electrophoretic separations.

A total of $3 \mu \mathrm{g} \mu \mathrm{L}^{-1}$ protein was added to $13 \mathrm{~cm}$ strips containing polyacrylamide gel with ampholytes immobilized at $\mathrm{pH} 3-10$. These strips were placed onto a first dimension focusing for $12 \mathrm{~h}$ at room temperature to be rehydrated with the protein extract. After this period, the strips were placed into an Ettan IPGphor isoelectric focusing (IEF) unit (GE Healthcare) for the first-dimension separation, after the strips were reduced for $10 \mathrm{~min}$ with a solution containing $6 \mathrm{~mol} \mathrm{~L}^{-1}$ urea, 2\% (w/v) SDS, 30\% (v/v) glycerol, $50 \mathrm{mmol} \mathrm{L}^{-1}$ Tris- $\mathrm{HCl}, 0.002 \%(\mathrm{w} / \mathrm{v})$ bromophenol blue and $2 \%(\mathrm{w} / \mathrm{v})$ DTT and alkylated for 10 min with a similar solution, but with DTT replaced by $2.5 \%(\mathrm{w} / \mathrm{v})$ iodoacetamide (IAA).

For the second dimension, the strips were placed onto a $10 \%$ polyacrylamide gel; a piece of filter paper with $10 \mu \mathrm{L}$ of a molecular weight standard (12-225 kDa range) was placed close to the strip in the gel, and they were sealed with a hot solution of $0.5 \%$ $(\mathrm{m} / \mathrm{v})$ agarose. The second dimension of the electrophoretic run was divided into two stages: $7.5 \mathrm{~mA} /$ gel for $30 \mathrm{~min}$ and $20 \mathrm{~mA} / \mathrm{gel}$ for $6 \mathrm{~h} 40 \mathrm{~min}$.

After the first and second dimensions in the electrophoretic runs, the proteins in the gels were fixed in the gels using a staining solution containing $10 \%(\mathrm{v} / \mathrm{v})$ acetic acid and $40 \%(\mathrm{v} / \mathrm{v})$ ethanol for $1 \mathrm{~h}$. In the sequence, the proteins were revealed with a colloidal Coomassie stain: $8 \%(\mathrm{~m} / \mathrm{v})$ ammonium sulfate, $1.6 \%(\mathrm{v} / \mathrm{v})$ phosphoric acid, 0.08\% (m/v) Coomassie blue G-250 and 25\% (v/v) methanol for $72 \mathrm{~h}$. Afterwards, the Coomassie stain was removed and the gels were washed with ultrapure water. The gels were scanned using an ImageScanner III (GE Healthcare), and the images were analyzed by ImageMaster 2D Platinum 7.0 (GeneBio, Geneva, Switzerland).

\subsection{Copper, magnesium, selenium and zinc mapping by FAAS or GFAAS}

The copper, selenium and zinc in the protein spots identified were determined by GFAAS, and magnesium was determined by FAAS after mineralizing the samples (spots and feed) as described by Moraes et al. [13]. The analyses used two different electrophoretic runs, and gels were obtained in duplicate for each run. The copper, magnesium, selenium and zinc determinations were performed with a Shimadzu AA-6800 atomic absorption spectrometer using wavelengths of 324.7, 285.2, 190.0 and $213.9 \mathrm{~nm}$, respectively. Copper, selenium and zinc operated with a current of $400 \mathrm{~mA}$ and magnesium with a current of $10 \mathrm{~mA}$. The analytical curves were prepared using Merck Titrisol standard solutions. The curves for copper and zinc were constructed in 
concentration ranges of $5.00-20.00 \mu \mathrm{gL}^{-1}$; for magnesium, the range was $0.10-0.40 \mathrm{mg} \mathrm{L}^{-1}$ and for selenium the range was $10.00-60.00 \mu \mathrm{g} \mathrm{L}^{-1}$. The region of the gel where no protein spots appeared was used for the analytical blank. The limits of quantification (LOQ) for copper, magnesium, selenium and zinc are 0.046 , $0.94,0.083$ and $0.023 \mu \mathrm{g} \mathrm{L}^{-1}$, respectively.

\subsection{Characterization of protein spots by ESI-MS/MS}

The protein spots were extracted from the gels using a scalpel, cut into segments of approximately $1 \mathrm{~mm}^{3}$ and prepared for MS according to Shevchenko et al. [14] with some modification. The subsequent procedure with the segments was described by the Waters' Technical Bulletin, which can be summed up in four steps: a) dye removal (destained with $25 \mathrm{mM}$ ammonium bicarbonate (Ambic)/acetonitrile (ACN) $(50: 50 \mathrm{v} / \mathrm{v})$, and after destaining, the fragments were dehydrated with two ACN baths for $10 \mathrm{~min}$ and dried at room temperature); b) reduction and alkylation (rehydrated with $20 \mathrm{mM}$ DTT in $50 \mathrm{mM}$ Ambic for $40 \mathrm{~min}$ at $56^{\circ} \mathrm{C}$; after time, the excess reagent was removed and $55 \mathrm{mM}$ IAA in $50 \mathrm{mM}$ Ambic was added for 30 min at room temperature); c) tryptic digestion of proteins (incubated overnight at $37^{\circ} \mathrm{C}$ with $10 \mathrm{ng} \mu \mathrm{L}^{-1}$ trypsin in $25 \mathrm{mM}$ Ambic for $15 \mathrm{~min}$; Trypsin Gold Mass Spectrometry, Promega, Madison, USA) and d) elution of peptides (extracted from gel by the addition of extraction buffer) A - 50\% ACN with $1 \%$ formic acid - to each tube and incubated for $15 \mathrm{~min}$ at $40^{\circ} \mathrm{C}$ under sonication; the supernatant was collected and transferred to a new tube, and this step was repeated with the extraction of buffer B $60 \%$ methanol with $1 \%$ formic acid - and extraction buffer C $-100 \%$ $\mathrm{ACN}$; the extracts were dried in a vacuum centrifuge and peptides were dissolved in $10 \mu \mathrm{L} 3 \%$ ACN with $0.1 \%$ formic acid. Aliquots of solutions containing peptides were analyzed by obtaining the mass spectra using the nanoACQUITY UPLC-Xevo QT-MS (Waters, Manchester, UK) system. Data was acquired over $20 \mathrm{~min}$, and the scan range was 50-2000 Da. ProteinLynx Global Server (PLGS) version 3.0 was used to process and search the continuum LC-MS ${ }^{\mathrm{E}}$ data, setting carbamidomethylation of cysteines as the fixed modification and oxidation of methionines as the variable modification, allowing one missing cleavage and a maximal error tolerance of $10 \mathrm{ppm}$ [15]. The identification of proteins was performed using the UniProt database (UniProtKB/Swiss-Prot - www.uniprot.org), and the search was conducted for the species Rattus norvegicus.

The UniProt protein IDs were converted to gene symbols in order to analyze them using Reactome Functional Interaction (FI) [16], a Cytoscape plugin [17]. Reactome uses a comparison with published knowledge about reactions, pathways and biological processes. Pathways with a false discovery rate (FDR) $<0.05$ were considered to be significantly enriched.

\section{Results and discussion}

\subsection{Protein separation by $2 D-P A G E$}

The total protein concentrations in the pool of pellets in the $C$, DM1 and DM1 + I groups were 131.12, 92.86 and $105.79 \mathrm{gL}^{-1}$ in the total extract and $26.09,20.05$ and $21.79 \mathrm{~g} \mathrm{~L}^{-1}$ precipitated with acetone, respectively. The pellets obtained with the acetone precipitation were used to calculate the volume of protein needed to obtain $3 \mu \mathrm{g} \mu \mathrm{L}^{-1}$ of protein to apply to the IEF strips. After standardization of the protocol to be followed, the gels obtained from different experimental groups were scanned and analyzed using ImageMaster 2D Platinum 7.0. The gels were compared in pairs because the imaging is a laborious process. After the identification of equivalent spots through the matching process, we obtained results of the correlation between the pairs of gels. The correlation between the gel replicates, encompassing the three electrophoretic runs (six gels from each group studied), were, on average in the $C$, DM1 and DM1 + I groups, 86\%, 79\% and 91\%, respectively.

Correlation between the protein spots from gels was determined, considering the percentage normalized volume (\%) during the matching process. The results obtained were as follows: G1 and $\mathrm{G} 2(\mathrm{R}>0.75), \mathrm{G} 1$ and $\mathrm{G} 3(\mathrm{R}>0.90)$ and $\mathrm{G} 2$ and $\mathrm{G} 3(\mathrm{R}>0.76)$. Through the correlation analysis, we can see that the proteomic profile of the $C$ group was closer to the proteomic profile of the DM1+I group than to the profile of the DM1 group. Most spots were distributed in the molecular weight (Mw) range of $31-76 \mathrm{kDa}$ with isoelectric points $(\mathrm{pI}) \cong 6$; in general, the Mw and $\mathrm{pI}$ distributions were homogeneous among the different experimental groups.

\subsection{Determination of $\mathrm{Cu}, \mathrm{Mg}$, Se and $\mathrm{Zn}$ in the spots}

The concentration of $\mathrm{Cu}, \mathrm{Mg}$, Se and $\mathrm{Zn}$ does not provide a lot of information without characterizing the proteins in these protein spots. Thus, we converted the estimate of the protein mass in the protein spots and the $\mathrm{Cu}, \mathrm{Mg}$, Se and $\mathrm{Zn}[18,19]$. Fig. $1 A$ shows the protein spots containing $\mathrm{Cu}, \mathrm{Mg}$, Se and/or Zn; Fig. $1 B-D$ shows the qualitative analyses that were used to identify the percentage of spots with $\mathrm{Cu}, \mathrm{Se}, \mathrm{Mg}$ and $\mathrm{Se}$. In the 75 spots analyzed, the $\mathrm{C}$ group showed the highest percentage of $\mathrm{Cu}$, the DM1 group showed the
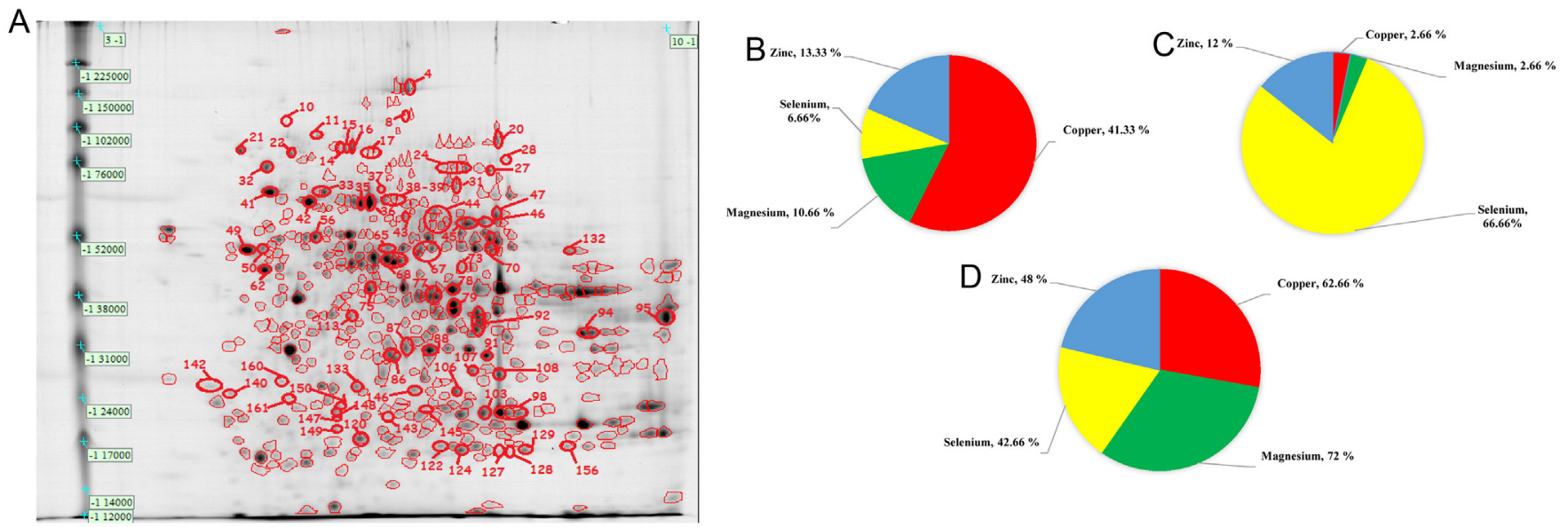

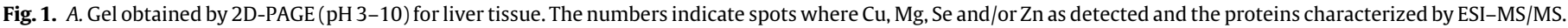

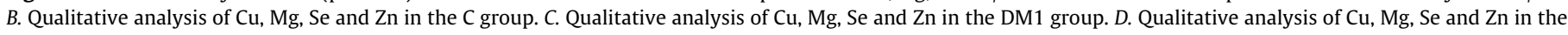
DM1 + I group. 
highest percentage of Se and the DM1 + I group showed the highest percentage of $\mathrm{Mg}$.

Se exerts a beneficial influence on health, including the prevention of cancer and neurodegenerative diseases, actuating the immune system and mainly in providing antioxidant capacity through selenoproteins [20]. The literature reports that a number of metals (copper, zinc, vanadium and cadmium) have ions that are capable of eliciting insulin mimetic effects by activating the insulin signaling cascade [21]. Recent epidemiological and intervention studies related high Se levels to hyperglycemia and dyslipidemia; for example, a study conducted using the US National Health and Nutrition Examination Surveys associated a high serum selenium concentration with an increased prevalence of diabetes [22,23], and the French SUVIMAX trial population associated positive correlations between plasma Se and fasting plasma glucose [24]. The effect of Se in carbohydrate metabolism is controversial, and the adverse effect on the insulin-regulated metabolic pathway could be a fake redox paradox that facilitates insulin action by an insulin- stimulated reactive oxygen species (ROS) [25], which could explain why most protein spots had Se presence, because most Se available can bind with proteins and interfere in their function and consequently in their pathways.

The feed was analyzed for $\mathrm{Cu}, \mathrm{Mg}$, Se and $\mathrm{Zn}$ in order to exclude the role of feed in the results of this work. We found the following concentrations: $\mathrm{Cu}: 2.36 \mathrm{mg} \mathrm{kg}^{-1}$, Mg: $28.90 \mathrm{mg} \mathrm{kg}^{-1}$, Se: < LOQ and $\mathrm{Zn}: 51.40 \mathrm{mg} \mathrm{kg}^{-1}$. Thus, the feed was observed to be a major source of $\mathrm{Mg}$ and $\mathrm{Zn}$.

Table 1 shows the $\mathrm{Cu}, \mathrm{Mg}$, Se and $\mathrm{Zn}$ concentrations determined in each protein spot with their respective Mw and pI and the protein mass measured using ImageMaster 2D Platinum 7.0 software.

\subsection{Protein spot analysis by ESI-MS/MS}

This study analyzed 75 spots of protein and found 114 different proteins that were associated with the presence of $\mathrm{Cu}, \mathrm{Mg}$, Se and/or $\mathrm{Zn}$ in the C, DM1 and DM1 + I groups, shown in Table 2. Reactome

Table 1

Values for copper, selenium and zinc concentration, determination by GFAAS and magnesium by FAAS in the protein spots for liver in different experimental groups.

\begin{tabular}{|c|c|c|c|c|c|c|c|c|c|c|c|c|c|c|c|c|c|c|c|c|c|}
\hline \multicolumn{8}{|c|}{ Control (c) } & \multicolumn{7}{|c|}{ Type 1 diabetes (DM1) } & \multicolumn{7}{|c|}{ Type 1 diabetes + Insulin (DM1+) } \\
\hline $\begin{array}{c}\text { Spot } \\
\text { ID }\end{array}$ & $\mathrm{pl}$ & 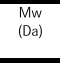 & $\begin{array}{l}\text { Prot, } \\
\text { mass } \\
(\mu g) \\
\end{array}$ & $\begin{array}{l}{[\mathrm{Cu}]} \\
(\mathrm{mg} \\
\left.\mathrm{g}^{-1}\right) \\
\end{array}$ & $\begin{array}{c}{[\mathrm{Mg}](\mathrm{mg}} \\
\left.\mathrm{g}^{-1}\right)\end{array}$ & {$[\mathrm{Se}]\left(\mathrm{mg} \mathrm{g}^{-1)}\right.$} & {$[\mathrm{zn}]\left(\mathrm{mg} \mathrm{g}^{-1)}\right.$} & $\mathrm{pl}$ & $\begin{array}{l}\begin{array}{l}M w \\
\text { (Da) }\end{array}\end{array}$ & $\begin{array}{c}\text { Prot. } \\
\text { mass( } \mu \mathrm{g} \\
)\end{array}$ & $\begin{array}{c}{[\mathrm{Cu}](\mathrm{mg}} \\
\left.\mathrm{g}^{-1)}\right)\end{array}$ & $\begin{array}{c}{[\mathrm{Mg}](\mathrm{mg}} \\
\left.\mathrm{g}^{-1}\right)\end{array}$ & $\begin{array}{c}{[\mathrm{Se}](\mathrm{mg}} \\
\left.\mathrm{g}^{-1)}\right)\end{array}$ & $\begin{array}{c}{[\mathrm{zn}](\mathrm{mg}} \\
\left.\mathrm{g}^{-1)}\right)\end{array}$ & $\mathrm{pl}$ & $\mathrm{Mw}$ (Da) & $\begin{array}{l}\text { Prot. } \\
\text { mass } \\
(\mu g)\end{array}$ & $\begin{array}{c}{[\mathrm{Cu}]} \\
\left(\mathrm{mg} \mathrm{g}^{-1}\right)\end{array}$ & $\begin{array}{c}{[\mathrm{Mg}](\mathrm{mg}} \\
\left.\mathrm{g}^{-1}\right)\end{array}$ & $\begin{array}{c}{[\mathrm{Se}]} \\
(\mathrm{mg} \\
\left.\mathrm{g}^{-1}\right) \\
\end{array}$ & $\begin{array}{l}{[\mathrm{Zn]}]} \\
\left(\mathrm{mg} \mathrm{g} \mathrm{g}^{-1)}\right.\end{array}$ \\
\hline 4 & & & & $\angle \angle O Q$ & $<\angle O Q$ & $<\angle O Q$ & $<\angle O Q$ & 6.86 & $\begin{array}{c}138,86 \\
5\end{array}$ & 2.62 & $<\angle O Q$ & $<\angle O Q$ & $\begin{array}{l}0.08 \pm \\
0.0024 \\
\end{array}$ & $<\angle O Q$ & 6.74 & 158,761 & 2.46 & $\begin{array}{l}0.07 \pm \\
0.0021 \\
\end{array}$ & $\begin{array}{l}0.29 \pm \\
0.0087\end{array}$ & $\angle L O Q$ & $<\angle O Q$ \\
\hline 8 & & & & $<\angle O Q$ & $<\angle O Q$ & $<\angle O Q$ & $<\angle O Q$ & 6.74 & $\begin{array}{c}104,12 \\
5\end{array}$ & 0.12 & $\angle L O Q$ & $<\angle O Q$ & $1.54 \pm 0.046$ & $\begin{array}{l}8.36 \pm \\
0.2508 \\
\end{array}$ & 6.69 & 126,372 & 0.13 & $\begin{array}{l}2.00 \pm \\
0.0600\end{array}$ & $\begin{array}{l}1.16 \pm \\
0.0348\end{array}$ & $\angle L O Q$ & $<\angle O Q$ \\
\hline 10 & & & & $<\angle O Q$ & $\angle L O Q$ & $\angle L O Q$ & $\angle L O Q$ & & & & $\angle \mathrm{LOQ}$ & $<\angle O Q$ & $\angle \mathrm{LOQ}$ & $<L O Q$ & 5.21 & 107,997 & 0.26 & $\begin{array}{l}1.80 \pm \\
0.0540\end{array}$ & $<\mathrm{LOQ}$ & $1.20 \pm 0.036$ & $\angle \angle O Q$ \\
\hline 11 & & & & $\angle L O Q$ & $\angle \mathrm{LOQ}$ & $\angle L O Q$ & $\angle L O Q$ & & & & $\angle L O Q$ & $\angle L O Q$ & $\angle \mathrm{LOQ}$ & $\angle \angle O Q$ & 5.21 & 107,997 & 0.26 & $\begin{array}{l}1.80 \pm \\
0.0540 \\
\end{array}$ & $\angle \mathrm{LOQ}$ & $1.20 \pm 0.036$ & $<\angle O Q$ \\
\hline 14 & & & & $<\angle O Q$ & $<\angle O Q$ & $<\angle O Q$ & $<\angle O Q$ & 5.96 & 80,910 & 0.37 & $<\angle O Q$ & $<\angle O Q$ & $1.14 \pm 0.034$ & $\begin{array}{l}16.68 \pm \\
0.5004 \\
\end{array}$ & 5.84 & 95,728 & 0.21 & $\begin{array}{l}4.75 \pm \\
0.1425 \\
\end{array}$ & $\begin{array}{l}11.41 \pm \\
0.3423 \\
\end{array}$ & $<\angle O Q$ & $<\angle O Q$ \\
\hline 15 & & & & $<\angle O Q$ & $\angle L O Q$ & $\angle L O Q$ & $\angle L O Q$ & 6.05 & 79,903 & 0.61 & $\angle L O Q$ & $<\angle O Q$ & $3.60 \pm 0.108$ & $\begin{array}{l}0.52 \pm \\
0.0156 \\
\end{array}$ & 5.91 & 94,630 & 0.50 & $\begin{array}{l}0.69 \pm \\
0.0207\end{array}$ & $\begin{array}{l}4.40 \pm \\
0.1320 \\
\end{array}$ & $\angle L O Q$ & $\begin{array}{l}1.87 \pm \\
0.0561\end{array}$ \\
\hline 16 & & & & $\angle \angle O Q$ & $\angle O Q$ & $\angle L O Q$ & $\angle L O Q$ & 6.12 & 80,910 & 0.50 & $\angle \angle O Q$ & $\angle \angle O Q$ & $\begin{array}{l}1.14 \pm \\
0.0342 \\
\end{array}$ & $<\angle O Q$ & 5.98 & 94,630 & 0.70 & $\begin{array}{l}0.44 \pm \\
0.0132 \\
\end{array}$ & $<\angle Q Q$ & $\angle L O Q$ & $\begin{array}{l}5.55 \pm \\
0.1665\end{array}$ \\
\hline 17 & & & & $<\angle O Q$ & $<\angle O Q$ & $\angle \mathrm{LOQ}$ & $<\angle O Q$ & 6.37 & 80,070 & 0.27 & $\angle L O Q$ & $<\angle O Q$ & $\begin{array}{l}1.01 \pm \\
0.0303\end{array}$ & $<\angle O Q$ & 6.26 & 93,275 & 0.26 & $\begin{array}{l}0.43 \pm \\
0.1329\end{array}$ & $\begin{array}{l}4.80 \pm \\
0.1440\end{array}$ & $1.02 \pm 0.0306$ & $<L O Q$ \\
\hline 20 & & & & $\angle \angle O Q$ & $\angle O Q$ & $\angle L O Q$ & $\angle L O Q$ & 7.86 & 85,065 & 0.97 & $\angle L O Q$ & $<\angle O Q$ & $\begin{array}{l}2.11 \pm \\
0.0633\end{array}$ & $<\angle O Q$ & 7.80 & 100,830 & 0.82 & $\begin{array}{l}0.15 \pm \\
0.0045\end{array}$ & $\begin{array}{l}1.72 \pm \\
0.0516\end{array}$ & $\angle L O Q$ & $<\angle O Q$ \\
\hline 21 & 4.75 & 82,042 & 0.89 & $\angle \angle O Q$ & $\begin{array}{l}1.25 \pm \\
0.0375\end{array}$ & $\angle L O Q$ & $<\angle O Q$ & 4.63 & 81,418 & 0.49 & $\angle \angle O Q$ & $<\angle O Q$ & $\begin{array}{c}2.49 \pm 0 \\
.0747\end{array}$ & $\angle L O Q$ & 4.64 & 92,471 & 0.62 & $\begin{array}{l}0.20 \pm \\
0.0060\end{array}$ & $\angle L O Q$ & $1.86 \pm 0.0558$ & $\angle \angle O Q$ \\
\hline 22 & & & & $<\angle O Q$ & $\angle \angle O Q$ & $<\angle O Q$ & $<\angle O Q$ & & & & $\angle L O Q$ & $<\angle O Q$ & $<\angle O Q$ & $<\angle O Q$ & 5.22 & 80,016 & 0.33 & $\begin{array}{l}0.53 \pm \\
0.0159 \\
\end{array}$ & $\begin{array}{l}3.42 \pm \\
0.1026 \\
\end{array}$ & $\angle L O Q$ & $\begin{array}{l}3.14 \pm \\
0.0942 \\
\end{array}$ \\
\hline 24 & & & & $<\angle O Q$ & $<\angle O Q$ & $<\angle O Q$ & $<\angle O Q$ & 7.34 & 68,267 & 0.29 & $<\angle O Q$ & $<\angle O Q$ & $\begin{array}{l}0.74 \pm \\
0.0222 \\
\end{array}$ & $<\angle O Q$ & \begin{tabular}{|l}
7.29 \\
\end{tabular} & 77,327 & 0.34 & $\begin{array}{l}0.53 \pm \\
0.0159 \\
\end{array}$ & $<\mathrm{LOQ}$ & $<\angle O Q$ & $<\angle O Q$ \\
\hline 27 & & & & $<\angle O Q$ & $<\angle O Q$ & $<\angle O Q$ & $<\angle O Q$ & & & & $<\angle O Q$ & $<\angle O Q$ & $<\mathrm{LOQ}$ & $<\angle O Q$ & 7.70 & 75,747 & 0.21 & $\begin{array}{l}0.17 \pm \\
0.0051\end{array}$ & $\begin{array}{l}0.15 \pm \\
0.0045 \\
\end{array}$ & $<\angle O Q$ & $<\angle O Q$ \\
\hline 28 & & & & $<\angle O Q$ & $\angle L O Q$ & $\angle L O Q$ & $\angle L O Q$ & 7.97 & 73,142 & 0.25 & $\angle L O Q$ & $<\angle O Q$ & $\begin{array}{l}4.46 \pm \\
0.1338 \\
\end{array}$ & $\begin{array}{l}7.82 \pm \\
0.2346 \\
\end{array}$ & 7.92 & 81,919 & 0.29 & $\begin{array}{l}0.07 \pm \\
0.0002 \\
\end{array}$ & $<\angle O Q$ & $<\angle O Q$ & $\angle \angle O Q$ \\
\hline 31 & & & & $\angle \angle O Q$ & $<\angle O Q$ & $\angle \angle O Q$ & $<\angle O Q$ & 7.34 & 68,267 & 0.29 & $\angle \angle O Q$ & $<\angle O Q$ & $\begin{array}{l}0.74 \pm \\
0.0222 \\
\end{array}$ & $<\angle O Q$ & 7.31 & 70,164 & 0.38 & $<\angle O Q$ & $\begin{array}{l}1.15 \pm \\
0.0345 \\
\end{array}$ & $0.81 \pm 0.0243$ & $<\angle O Q$ \\
\hline 32 & & & & $<\angle O Q$ & $\angle L O Q$ & $\angle \angle O Q$ & $<\angle O Q$ & & & & $\angle \angle O Q$ & $<\angle O Q$ & $<\angle O Q$ & $\angle \mathrm{LQQ}$ & 4.98 & 80,514 & 1.11 & $\begin{array}{l}0.32 \pm \\
0.0096\end{array}$ & $\begin{array}{l}0.18 \pm \\
0.0054 \\
\end{array}$ & $\angle L O Q$ & $<\angle O Q$ \\
\hline 33 & & & & $<\angle O Q$ & $<\angle O Q$ & $\angle \angle O Q$ & $<\angle O Q$ & & & & $<\angle O Q$ & $<\angle O Q$ & $<\angle O Q$ & $<\angle O Q$ & 5.62 & 70,282 & 0.56 & $\begin{array}{l}0.82 \pm \\
0.0246\end{array}$ & $\begin{array}{l}3.12 \pm \\
0.0936\end{array}$ & $0.30 \pm 0.0090$ & $\begin{array}{l}8.34 \pm \\
0.2502\end{array}$ \\
\hline 35 & & & & $<\angle O Q$ & $\angle \mathrm{LOQ}$ & $<\angle O Q$ & $<\angle O Q$ & 6.22 & 59,239 & 1.24 & $<\angle O Q$ & $<\angle O Q$ & $\begin{array}{l}1.39 \pm \\
0.0417\end{array}$ & $\begin{array}{l}4.66 \pm \\
0.1398\end{array}$ & \begin{tabular}{|l|l|}
6.09 \\
\end{tabular} & 66,084 & 1.28 & $\begin{array}{l}0.51 \pm \\
0.153\end{array}$ & $<\angle O Q$ & $0.11 \pm 0.0033$ & $<\angle O Q$ \\
\hline 36 & & & & $\angle L O Q$ & $\angle L Q$ & $\angle L O Q$ & $\angle L O Q$ & 6.12 & 80,910 & 0.50 & $\angle L O Q$ & $<\angle O Q$ & $1.14 \pm 0.0342$ & $<\angle O Q$ & 6.19 & 66,084 & 4.49 & $\begin{array}{l}0.09 \pm \\
0.0027\end{array}$ & $\begin{array}{l}0.60 \pm \\
0.0180 \\
\end{array}$ & $\angle L O Q$ & $\begin{array}{l}0.11 \pm \\
0.0033 \\
\end{array}$ \\
\hline 37 & 7.65 & 48,290 & 1.41 & $\begin{array}{r}3.38 \pm \\
0.1014 \\
\end{array}$ & $\angle O Q$ & $\angle \mathrm{LOQ}$ & $<\angle O Q$ & & & & $\angle \angle Q Q$ & $<\angle O Q$ & $\angle \angle O Q$ & $\angle O Q$ & & & & $<\angle O Q$ & $<\angle Q$ & $\angle O Q Q$ & $<\angle O Q$ \\
\hline 38-39 & & & & $<\angle O Q$ & $\angle \angle O Q$ & $\angle L O Q$ & $<\angle O Q$ & 6.71 & 59,815 & 0.34 & $\angle L O Q$ & $<\angle O Q$ & $\begin{array}{l}0.88 \pm \\
0.0264 \\
\end{array}$ & $\begin{array}{l}0.72 \pm \\
0.0216 \\
\end{array}$ & 6.54 & 66,823 & 0.23 & $\begin{array}{l}2.29 \pm \\
0.0687 \\
\end{array}$ & $\begin{array}{l}0.65 \pm \\
0.0195 \\
\end{array}$ & $0.97 \pm 0.0291$ & $<\angle O Q$ \\
\hline 41 & & & & $<\angle O Q$ & $\angle L O Q$ & $\angle \mathrm{LOQ}$ & $\angle \angle O Q$ & 5.04 & 63,227 & 1.58 & $\angle L O Q$ & $<\angle O Q$ & $0.48 \pm 0.0144$ & $<\mathrm{LOQ}$ & 5.03 & 69,006 & 1.97 & $\begin{array}{l}0.36 \pm \\
0.108 \\
\end{array}$ & $\begin{array}{l}0.66 \pm \\
0.0198 \\
\end{array}$ & $\angle L O Q$ & $<\angle O Q$ \\
\hline 42 & & & & $\angle \angle O Q$ & $\angle L O Q$ & $\angle \angle O Q$ & $\angle \angle O Q$ & 5.56 & 59,695 & 1.73 & $\angle \angle O Q$ & $\angle \angle O Q$ & $\begin{array}{l}0.73 \pm \\
0.0219 \\
\end{array}$ & $<\angle O Q$ & 5.50 & 66.126 & 0.88 & $\begin{array}{l}0.23 \pm \\
0.0069 \\
\end{array}$ & $\angle \mathrm{LQQ}$ & $2.40 \pm 0.0720$ & $\begin{array}{r}91.65 \pm \\
2.7495 \\
\end{array}$ \\
\hline 43 & & & & $<\angle O Q$ & $\angle L O Q$ & $<\angle O Q$ & $<\angle O Q$ & & & & $\angle L O Q$ & $<\angle O Q$ & $<\angle O Q$ & $\angle O Q$ & \begin{tabular}{|l|l|}
6.67 & \\
\end{tabular} & 60,807 & 0.27 & $\begin{array}{l}2.05 \pm \\
0.0615 \\
\end{array}$ & $\begin{array}{l}4.13 \pm \\
0.1239\end{array}$ & $4.36 \pm 0.1308$ & $<\angle O Q$ \\
\hline 44 & 7.17 & 56,576 & 0.30 & $\angle L O Q$ & $\begin{array}{l}0.59 \pm \\
0.0177 \\
\end{array}$ & $\angle L O Q$ & $\angle L O Q$ & & & & $\angle L O Q$ & $\angle L O Q$ & $\angle \angle O Q$ & $\angle L O Q$ & & & & $<\angle O Q$ & $<\angle O Q$ & $\angle O Q$ & $\angle \mathrm{LOQ}$ \\
\hline 45 & & & & $\angle \angle O Q$ & $<\angle O Q$ & $\angle \angle O Q$ & $\angle \angle O Q$ & 7.44 & 53,314 & 0.85 & $\angle \angle O Q$ & $\angle \angle O Q$ & $\begin{array}{l}1.65 \pm \\
0.0495 \\
\end{array}$ & $\angle \angle O Q$ & 7.40 & 58,921 & 0.72 & $\begin{array}{l}0.85 \pm \\
0.0255 \\
\end{array}$ & $\begin{array}{l}5.66 \pm \\
0.1698 \\
\end{array}$ & $\angle L O Q$ & $\begin{array}{l}11.76 \pm \\
0.3528 \\
\end{array}$ \\
\hline 46 & 7.75 & 55,426 & 0.81 & $<\angle O Q$ & $\angle L O Q$ & $\begin{array}{l}0.10 \pm \\
0.0030\end{array}$ & $<\angle O Q$ & 7.68 & 49,569 & 0.46 & $\angle \angle O Q$ & $<\angle O Q$ & $\begin{array}{l}0.84 \pm \\
0.0252 \\
\end{array}$ & $\begin{array}{l}3.82 \pm \\
0.1146 \\
\end{array}$ & 7.57 & 59,115 & 0.35 & $\begin{array}{l}1.63 \pm \\
0.0489 \\
\end{array}$ & $\begin{array}{l}3.30 \pm \\
0.0990 \\
\end{array}$ & $1.89 \pm 0.0567$ & \\
\hline 47 & & & & $<L O Q$ & $<\angle O Q$ & $<L O Q$ & $<\angle O Q$ & 6.65 & 43,490 & 2.14 & $<\angle O Q$ & $<\angle O Q$ & $\begin{array}{l}1.92 \pm \\
0.0576\end{array}$ & $<L O Q$ & \begin{tabular}{|l|}
7.82 \\
\end{tabular} & 59,365 & 0.56 & $\begin{array}{l}1.54 \pm \\
0.0462\end{array}$ & $\begin{array}{l}1.66 \pm \\
0.0498\end{array}$ & $0.01 \pm 0.0003$ & $\begin{array}{l}6.39 \pm \\
0.1917\end{array}$ \\
\hline 49 & & & & $\angle \angle O Q$ & $\angle L Q$ & $\angle \angle O Q$ & $\angle L O Q$ & 4.70 & 47,123 & 2.75 & $\angle L O Q$ & $<\angle O Q$ & $\begin{array}{l}0.44 \pm \\
0.0132\end{array}$ & $<\angle O Q$ & 4.76 & 51,827 & 2.45 & $\begin{array}{l}0.16 \pm \\
0.0048\end{array}$ & $\begin{array}{l}0.82 \pm \\
0.0246\end{array}$ & $0.47 \pm 0.0141$ & $<\angle O Q$ \\
\hline 50 & & & & $\angle L O Q$ & $\angle L O Q$ & $\angle L O Q$ & $\angle L O Q$ & 5.43 & 41,025 & 0.35 & $\angle L O Q$ & $\begin{array}{l}6.14 \pm \\
0.1842 \\
\end{array}$ & $\begin{array}{l}2.95 \pm \\
0.0885 \\
\end{array}$ & $\angle L O Q$ & 3.86 & 53,581 & 0.90 & $\begin{array}{l}0.14 \pm \\
0.0042 \\
\end{array}$ & $\begin{array}{l}0.48 \pm \\
0.0144 \\
\end{array}$ & $\angle L O Q$ & $\angle O Q Q$ \\
\hline 56 & & & & $<\angle O Q$ & $\angle \angle O Q$ & $\angle \mathrm{LOQ}$ & $<\angle O Q$ & 6.06 & 50,138 & 1.24 & $\angle \angle O Q$ & $<\angle O Q$ & $\begin{array}{l}2.63 \pm \\
0.0789 \\
\end{array}$ & $<\angle Q Q$ & 5.46 & 55,395 & 0.63 & $\begin{array}{l}0.61 \pm \\
0.0183 \\
\end{array}$ & $\angle \mathrm{LQQ}$ & $0.53 \pm 0.0159$ & $<\angle O Q$ \\
\hline 60 & 7.83 & 50,912 & 0.75 & $<\angle O Q$ & $<\angle O Q$ & $\angle \mathrm{LOQ}$ & $\begin{array}{l}5.21 \pm \\
0.1563 \\
\end{array}$ & 7.68 & 49,569 & 0.46 & $\angle \angle O Q$ & $<\angle O Q$ & $\begin{array}{l}0.84 \pm \\
0.0252 \\
\end{array}$ & $\begin{array}{r}3.82 \pm \\
0.1146 \\
\end{array}$ & 7.65 & 54,575 & 0.63 & $\begin{array}{l}9.72 \pm \\
0.2916 \\
\end{array}$ & $\begin{array}{l}1.17 \pm \\
0.0351 \\
\end{array}$ & $0.77 \pm 0.0231$ & $\begin{array}{l}24.27 \pm \\
0.7281 \\
\end{array}$ \\
\hline 62 & 5.05 & 43,140 & 1.65 & $\angle \angle O Q$ & $\angle L O Q$ & $\angle \angle O Q$ & $\begin{array}{l}2.56 \pm \\
0.0768 \\
\end{array}$ & & & & $\angle L O Q$ & $\angle L O Q$ & $\angle \mathrm{LOQ}$ & $\angle \mathrm{LOQ}$ & 4.99 & 46,890 & 2.51 & $<\angle O Q$ & $\angle \angle O Q$ & $0.94 \pm 0.0282$ & $<\angle O Q$ \\
\hline 65 & 6.57 & 48,632 & 0.52 & $\angle L O Q$ & $\angle L O Q$ & $\angle \angle O Q$ & $\begin{array}{l}5.33 \pm \\
0.1599 \\
\end{array}$ & 6.55 & 45,951 & 1.07 & $\angle L O Q$ & $\angle L O Q$ & $\begin{array}{l}0.58 \pm \\
0.0174 \\
\end{array}$ & $\angle L O Q$ & 6.78 & 54,481 & 0.42 & $\begin{array}{l}1.97 \pm \\
0.0591 \\
\end{array}$ & $\begin{array}{l}6.45 \pm \\
0.1935 \\
\end{array}$ & $1.40 \pm 0.0420$ & $\angle \angle O Q$ \\
\hline 67 & & & & $<\angle O Q$ & $\angle O Q Q$ & $<\angle O Q$ & $<\mathrm{LOQ}$ & 6.98 & 46,486 & 0.55 & $\begin{array}{c}11.00 \pm \\
0.33\end{array}$ & $<\angle O Q$ & $\begin{array}{l}1.84 \pm \\
0.0552 \\
\end{array}$ & $\angle O Q$ & 6.95 & 50,547 & 0.77 & $\begin{array}{l}1.20 \pm \\
0.0360 \\
\end{array}$ & $\begin{array}{l}2.72 \pm \\
0.0816 \\
\end{array}$ & $0.63 \pm 0.0189$ & $\begin{array}{l}2.15 \pm \\
0.0645 \\
\end{array}$ \\
\hline 68 & & & & $<\angle O Q$ & $\angle L Q$ & $\angle L O Q$ & $\angle L O Q$ & 6.60 & 44,720 & 1.6 & $<\angle O Q$ & $<\angle O Q$ & $\begin{array}{l}1.25 \pm \\
0.0375 \\
\end{array}$ & $\angle \mathrm{LOQ}$ & 6.50 & 48,730 & 1.91 & $\begin{array}{l}0.25 \pm \\
0.0075 \\
\end{array}$ & $\begin{array}{l}0.14 \pm \\
0.0042 \\
\end{array}$ & $0.66 \pm 0.0198$ & $\begin{array}{r}5.83 \pm \\
0.1749 \\
\end{array}$ \\
\hline 70 & & & & $<\angle O Q$ & $\angle O Q$ & $\angle O Q$ & $<\angle O Q$ & 7.68 & 49,569 & 0.46 & $\angle O Q Q$ & $<\angle O Q$ & $\begin{array}{l}0.84 \pm \\
0.0252 \\
\end{array}$ & $\begin{array}{l}3.82 \pm \\
0.1056 \\
\end{array}$ & 7.69 & 51,482 & 1.13 & $\begin{array}{l}0.59 \pm \\
0.0177 \\
\end{array}$ & $\begin{array}{l}6.16 \pm \\
0.1848 \\
\end{array}$ & $\angle \angle Q Q$ & $\begin{array}{r}12.83 \pm \\
0.3849 \\
\end{array}$ \\
\hline 73 & & & & $\angle L O Q$ & $\angle \angle O Q$ & $\angle \angle O Q$ & $<\angle O Q$ & & & & $\angle L O Q$ & $<\angle O Q$ & $<\angle O Q$ & $<L O Q$ & 7.05 & 61,417 & 0.79 & $\begin{array}{l}0.34 \pm \\
0.0102\end{array}$ & $\begin{array}{r}2.43 \pm \\
0.0729\end{array}$ & $0.18 \pm 0.0054$ & $\begin{array}{l}0.65 \pm \\
0.0195\end{array}$ \\
\hline 75 & & & & $<\angle O Q$ & $\angle \mathrm{LOQ}$ & $<\mathrm{LOQ}$ & $<\angle O Q$ & 6.31 & 38,278 & 0.59 & $\angle O O Q$ & $<\angle O Q$ & $\begin{array}{l}0.29 \pm \\
0.0087 \\
\end{array}$ & $<\angle Q Q$ & 5.92 & 40,622 & 0.33 & $\begin{array}{l}1.83 \pm \\
0.0549 \\
\end{array}$ & $\begin{array}{l}8.55 \pm \\
0.2565 \\
\end{array}$ & $3.13 \pm 0.0939$ & $\begin{array}{l}49.52 \pm \\
1.4856 \\
\end{array}$ \\
\hline 77 & 7.08 & 38,070 & 0.75 & $\angle L O Q$ & $\begin{array}{l}0.63 \pm \\
0.0189 \\
\end{array}$ & $\angle L O Q$ & $\angle L O Q$ & 7.05 & 38,060 & 1.13 & $\angle L O Q$ & $\angle L O Q$ & $\begin{array}{l}0.31 \pm \\
0.0093 \\
\end{array}$ & $\angle L O Q$ & 7.05 & 40,063 & 1.40 & $\begin{array}{l}0.36 \pm \\
0.0108 \\
\end{array}$ & $\begin{array}{l}1.64 \pm \\
0.0492 \\
\end{array}$ & $0.50 \pm 0.0150$ & $\begin{array}{l}8.68 \pm \\
0.2604 \\
\end{array}$ \\
\hline
\end{tabular}


Table 1 (Continued)

\begin{tabular}{|c|c|c|c|c|c|c|c|c|c|c|c|c|c|c|c|c|c|c|c|c|c|}
\hline 78 & 7.36 & 38,812 & 2.32 & $\angle L O Q$ & $\begin{array}{l}0.20 \pm \\
0.0060\end{array}$ & $<\angle O Q$ & $\begin{array}{l}2.17 \pm \\
0.0651\end{array}$ & 7.27 & 37,890 & 1.66 & $<\angle O Q$ & $\begin{array}{l}0.15 \pm \\
0.0045\end{array}$ & $\begin{array}{l}0.93 \pm \\
0.0279\end{array}$ & $<\mathrm{LQQ}$ & $\mid$\begin{tabular}{||l}
$\mid 7.26$ \\
\end{tabular} & 41,861 & 1.77 & $\begin{array}{l}0.15 \pm \\
0.0045\end{array}$ & $\begin{array}{l}1.77 \pm \\
0.0531\end{array}$ & $<\angle O Q$ & $<\angle O Q$ \\
\hline 79 & 7.38 & 36,070 & 2.09 & $\angle L O Q$ & $\angle \angle O Q$ & $\angle \angle O Q$ & $\begin{array}{l}1.11 \pm \\
0.0333\end{array}$ & 7.27 & 35,188 & 1.93 & $\angle \angle O Q$ & $<\angle O Q$ & $\begin{array}{l}0.53 \pm \\
0.0159\end{array}$ & $\angle L O Q$ & \begin{tabular}{|l|l|l|l|l|}
7.27 \\
\end{tabular} & 38,265 & 1.64 & $\begin{array}{l}0.25 \pm \\
0.0075\end{array}$ & $\begin{array}{l}1.44 \pm \\
0.0432\end{array}$ & $\angle \angle O Q$ & $\begin{array}{l}21.63 \pm \\
0.6489\end{array}$ \\
\hline 86 & 6.59 & 29,608 & 0.84 & $\begin{array}{l}0.05 \pm \\
0.0015\end{array}$ & $\angle \angle O Q$ & $\angle \mathrm{LOQ}$ & $<\angle O Q$ & 6.54 & 29,852 & 0.61 & $\angle L O Q$ & $\angle \mathrm{LOQ}$ & $0.30 \pm 0.009$ & $\angle L O Q$ & 6.46 & 31,747 & 1.26 & $<\angle O Q$ & $\begin{array}{l}3.06 \pm \\
0.0918\end{array}$ & $\angle \angle O Q$ & $<\angle O Q$ \\
\hline 87 & 6.79 & 30,496 & 0.95 & $\begin{array}{l}0.05 \pm \\
0.0015\end{array}$ & $<\angle O Q$ & $<\angle Q Q$ & $<\angle O Q$ & & & & $<\angle O Q$ & $<\angle O Q$ & $<\angle O Q$ & $<\angle O Q$ & \begin{tabular}{|l|l|l}
6.67 \\
\end{tabular} & 33,737 & 1.03 & $<\angle O Q$ & $\begin{array}{l}.52 \pm \\
0.1056\end{array}$ & $0.76 \pm 0.0228$ & $\begin{array}{l}4.00 \pm \\
0.1200\end{array}$ \\
\hline 88 & 7.08 & 30,197 & 1.84 & $\begin{array}{l}0.10 \pm \\
0.0030\end{array}$ & $<\mathrm{LOQ}$ & $<\angle O Q$ & $<\angle O Q$ & 7.55 & 38,668 & 0.96 & $<\angle O Q$ & $\angle \mathrm{LOQ}$ & $\begin{array}{l}0.91 \pm \\
0.0273\end{array}$ & $<\mathrm{LOQ}$ & \begin{tabular}{|ll}
7.19 \\
\end{tabular} & 33,206 & 0.56 & $<\angle O Q$ & $\begin{array}{l}5.05 \pm \\
0.1515\end{array}$ & $\angle \mathrm{LOQ}$ & $\begin{array}{l}18.18 \pm \\
0.5454\end{array}$ \\
\hline 91 & & & & $\angle L O Q$ & $<\angle O Q$ & $<\angle O Q$ & $<\angle O Q$ & 7.65 & 27,962 & 2.32 & $<\angle O Q$ & $<\angle O Q$ & $0.57 \pm 0.171$ & $<\angle O Q$ & 7.63 & 32,597 & 1.93 & $\begin{array}{l}0.02 \pm \\
0.0006\end{array}$ & $\begin{array}{l}0.12 \pm \\
0.0336\end{array}$ & $<\angle O Q$ & $\begin{array}{l}10.028 \pm \\
0.3084\end{array}$ \\
\hline 92 & 6.62 & 29,320 & 0.79 & $\begin{array}{l}0.53 t \\
0.0159\end{array}$ & $<\angle O Q$ & $<\angle 0 Q$ & $<L O Q$ & & & & $\angle \angle O Q$ & $<L O Q$ & $<\angle O Q$ & $<\angle O Q$ & 7.66 & 35,393 & 1.02 & $\begin{array}{l}0.23 \pm \\
0.0069\end{array}$ & $\begin{array}{l}3.19 \pm \\
0.0957\end{array}$ & $0.82 \pm 0.0246$ & $\begin{array}{l}18.18 \pm \\
0.5454\end{array}$ \\
\hline 94 & 9.19 & 32,597 & 0.94 & $\begin{array}{l}0.13 \pm \\
0.0039 \\
\end{array}$ & $<\angle O Q$ & $<\angle O Q$ & $<\angle O Q$ & 9.02 & 28,940 & 0.21 & $\angle \angle O Q$ & $\angle L Q$ & $\begin{array}{l}3.77 \pm \\
0.1131 \\
\end{array}$ & $\angle \angle O Q$ & 9.26 & 37,304 & 1.74 & $<L O Q$ & $\begin{array}{l}2.20 \pm \\
0.0660 \\
\end{array}$ & $0.03 \pm 0.0009$ & $\begin{array}{l}13.35 \pm \\
0.4005 \\
\end{array}$ \\
\hline 95 & 10.04 & 35,405 & 2.99 & $\begin{array}{l}0.03 \pm \\
0009\end{array}$ & $<\angle O Q$ & $\angle \angle O Q$ & $<\angle O Q$ & 9.96 & 36,471 & 1.59 & $<\angle O Q$ & $<\angle O Q$ & $\begin{array}{l}6.26 \pm \\
0.1878\end{array}$ & $<\angle O Q$ & 9.96 & 38,000 & 1.15 & $<\angle O Q$ & $\begin{array}{l}4.05 \pm \\
0.1215\end{array}$ & $1.22 \pm 0.0366$ & $\begin{array}{l}5.04 \pm \\
0.1512\end{array}$ \\
\hline 98 & 8.23 & 19,171 & 4.23 & $\begin{array}{l}0.30 \pm \\
0.0090\end{array}$ & $<\mathrm{LOQ}$ & $<\angle O Q$ & $<L O Q$ & 8.05 & 19,525 & 0.97 & $<\angle O Q$ & $\angle \mathrm{LOQ}$ & $\begin{array}{l}0.1010 \\
2.15 \pm \\
0.0645\end{array}$ & $<\angle O Q$ & 8.13 & 18,437 & 0.49 & $\begin{array}{l}0.31 \pm \\
0.0093\end{array}$ & $\begin{array}{l}.11 .92 \pm \\
0.3576\end{array}$ & $\angle \mathrm{LOQ}$ & $\begin{array}{c}0.1512 \pm \\
2.72 \pm \\
0.0816\end{array}$ \\
\hline 103 & 7.74 & 21,061 & 1.26 & $\begin{array}{l}0.52 \pm \\
0.0156\end{array}$ & $<\angle O Q$ & $<\angle O Q$ & $<\angle Q Q$ & & & & $<\angle 0 Q$ & $<\angle O Q$ & LOQ & $<\angle O Q$ & & & & $<\angle O Q$ & $<\angle O Q$ & $<\angle O Q$ & $<\angle O Q$ \\
\hline 106 & 7.41 & 24,638 & 0.76 & $\begin{array}{l}0.73 \pm \\
0.0219\end{array}$ & $\begin{array}{l}0.62 \pm \\
0.186\end{array}$ & $\begin{array}{l}6.29 \pm \\
0.1887\end{array}$ & $<\angle O Q$ & 7.43 & 29,162 & 1.49 & $\angle \angle O Q$ & $<\angle O Q$ & $\begin{array}{l}1.29 \pm \\
0.0387\end{array}$ & $\angle \angle O Q$ & 5.32 & 24,806 & 0.07 & $\angle \angle O Q$ & $\begin{array}{l}87.04 \pm \\
2.6112\end{array}$ & $<\angle O Q$ & $\begin{array}{c}110.29 \pm \\
3.3087\end{array}$ \\
\hline 107 & 7.60 & 27,366 & 0.50 & $\begin{array}{l}21.03 \pm \\
0.6309\end{array}$ & $\angle \mathrm{LOQ}$ & $\begin{array}{l}12.48 \pm \\
0.3744\end{array}$ & $<\angle O Q$ & & & & $\angle \angle O Q$ & $\angle \mathrm{LOQ}$ & $<\mathrm{LOQ}$ & $<\angle O Q$ & \begin{tabular}{|l|l|l}
7.47 & \\
\end{tabular} & 30,618 & 0.59 & $\begin{array}{l}0.83 \pm \\
0.0249\end{array}$ & $\begin{array}{l}5.31 \pm \\
0.1593\end{array}$ & $\angle \angle O Q$ & $\begin{array}{l}31.27 \pm \\
0.9381\end{array}$ \\
\hline 108 & 7.94 & 26,921 & 1.40 & $\begin{array}{l}0.86 \pm \\
0.258\end{array}$ & $\begin{array}{l}0.07 \pm \\
0.0021\end{array}$ & $\begin{array}{l}3.05 \pm \\
0.915\end{array}$ & $<\angle O Q$ & 7.29 & 23,018 & 0.41 & $<\angle O Q$ & $<\angle O Q$ & $\begin{array}{l}2.24 \pm \\
0.0672\end{array}$ & $<\angle O Q$ & \begin{tabular}{|l|l|l}
7.81 &
\end{tabular} & 29,869 & 0.76 & $\begin{array}{l}0.79 \pm \\
0.0237\end{array}$ & $\begin{array}{l}4.84 \pm \\
0.1452\end{array}$ & $\angle \mathrm{LOQ}$ & $\begin{array}{l}26.66 \pm \\
0.7998\end{array}$ \\
\hline 113 & 6.11 & 34,878 & 0.32 & $\begin{array}{l}7.57 \pm \\
0.2271\end{array}$ & $\angle \mathrm{LOQ}$ & $<\angle O Q$ & $<\angle O Q$ & 6.02 & 37,126 & 0.38 & $<\angle O Q$ & $<\angle O Q$ & $\begin{array}{l}6.14 \pm \\
0.1842\end{array}$ & $<\angle O Q$ & \begin{tabular}{|l|}
5.99 \\
\end{tabular} & 37,205 & 0.46 & $\begin{array}{l}4.54 \pm \\
0.1362\end{array}$ & $\begin{array}{l}5.24 \pm \\
0.1572\end{array}$ & $\angle L O Q$ & $\begin{array}{l}32.89 \pm \\
0.9867\end{array}$ \\
\hline 120 & 6.22 & 17,269 & 0.88 & $\begin{array}{l}0.53 \pm \\
0.0159\end{array}$ & $<\angle O Q$ & $<\angle O Q$ & $\begin{array}{l}27.97 \pm \\
0.8391\end{array}$ & 6.45 & 17,000 & 0.47 & $<\angle O Q$ & $<\angle Q$ & $\begin{array}{l}2.80 \pm \\
0.0840\end{array}$ & $<\angle O Q$ & 6.11 & 19,396 & 1.60 & $\begin{array}{l}1.58 \pm \\
0.0474\end{array}$ & $\begin{array}{l}2.40 \pm \\
0.0720\end{array}$ & $0.47 \pm 0.0141$ & $\begin{array}{l}8.45 \pm \\
0.2535\end{array}$ \\
\hline 122 & 5.88 & 24,964 & 0.53 & $\begin{array}{l}7.76 \pm \\
0.2328\end{array}$ & $<\angle O Q$ & $<\angle O Q$ & $<\angle O Q$ & 7.23 & 16,514 & 0.28 & $\begin{array}{l}12.23 \pm \\
0.3669\end{array}$ & $<\angle O Q$ & $\begin{array}{l}7.52 \pm \\
0.2256\end{array}$ & $<\angle O Q$ & 7.15 & 20,613 & 0.86 & $<\angle O Q$ & $\begin{array}{l}4.71 \pm \\
0.1413\end{array}$ & $<\angle O Q$ & $\begin{array}{l}0.49 \pm \\
0.0147\end{array}$ \\
\hline 124 & 7.47 & 16,269 & 0.88 & $\begin{array}{r}1.48 \pm \\
0.0444 \\
\end{array}$ & $<\angle O Q$ & $<\angle O Q$ & $<\angle O Q$ & & & & $\angle \mathrm{LOQ}$ & $<\angle O Q$ & $\angle L O Q$ & $<\angle O Q$ & & & & $<\angle O Q$ & $\angle \angle O Q$ & $\angle \angle O Q$ & $<\angle O Q$ \\
\hline 127 & 7.94 & 16,168 & 0.23 & $\begin{array}{l}4.64 \pm \\
0.1394\end{array}$ & $<\angle O Q$ & $<\angle Q$ & $<\angle O Q$ & 7.77 & 18,195 & 0.77 & $<\angle O Q$ & $\begin{array}{l}0.30 \pm \\
0.0090\end{array}$ & $\begin{array}{r}2.96 \pm \\
0.0888\end{array}$ & $<\angle O Q$ & & & & $<\angle O Q$ & $<\angle O Q$ & $<\angle O Q$ & $<\llcorner O Q$ \\
\hline 128 & 8.06 & 16,168 & 0.20 & $\begin{array}{c}0.1594 \\
2.19 \pm 0 . \\
0657\end{array}$ & $<\angle O Q$ & $<\angle O Q$ & $<\angle O Q$ & & & & $<\angle O Q$ & $<\mathrm{LOQ}$ & $\angle 0.0000$ & $<\angle O Q$ & & & & $<\angle O Q$ & $<\angle O Q$ & $<\angle O Q$ & $<\angle O Q$ \\
\hline 129 & 8.26 & 16,269 & 0.50 & $\begin{array}{r}2.5 \pm \\
0.0774\end{array}$ & $<\angle O Q$ & $\begin{array}{l}1.51 \pm \\
0.0453\end{array}$ & $<\angle O Q$ & & & & $<\angle O Q$ & $<\angle O Q$ & $\angle L O Q$ & $<\angle O Q$ & & & & $<\angle O Q$ & $<\angle O Q$ & $<\angle O Q$ & $<\angle O Q$ \\
\hline 132 & 8.91 & 47,783 & 0.32 & $\begin{array}{l}0.98 \pm \\
0.0294\end{array}$ & $\angle \angle O Q$ & $<\angle O Q$ & $<\angle O Q$ & & & & $\angle \mathrm{LOQ}$ & $\angle \mathrm{LOQ}$ & $<\angle O Q$ & $<\angle O Q$ & 8.83 & 51,654 & 0.51 & $\begin{array}{l}0.87 \pm \\
0.0261\end{array}$ & $\begin{array}{l}4.43 \pm \\
0.1329\end{array}$ & $2.00 \pm 0.0600$ & $\begin{array}{l}1.51 \pm \\
0.0453\end{array}$ \\
\hline 133 & 6.18 & 25,294 & 0.54 & $\begin{array}{l}0.72 \pm \\
0.0216\end{array}$ & $\angle O Q$ & $\angle L O Q$ & $<\angle O Q$ & & & & $<\angle O Q$ & $<\angle O Q$ & $\angle L O Q$ & $<\angle O Q$ & 5.99 & 37,205 & 0.46 & $\begin{array}{l}4.54 \pm \\
0.1362\end{array}$ & $\begin{array}{l}5.24 \pm \\
0.1572\end{array}$ & $\angle L O Q$ & $\begin{array}{l}32.89 \pm \\
0.9867\end{array}$ \\
\hline 140 & 4.63 & 24,397 & 0.21 & $\begin{array}{l}7.43 \pm \\
0.2229\end{array}$ & $\begin{array}{l}1.71 \pm \\
0.0351\end{array}$ & $<\angle O Q$ & $\begin{array}{l}9.53 \pm \\
0.2859\end{array}$ & 4.62 & 20,101 & 0.44 & $<L O Q$ & $<\angle O Q$ & $\begin{array}{l}2.25 \pm \\
0.0675\end{array}$ & $<L O Q$ & & & & $<L O Q$ & $<\angle O Q$ & $\angle L Q$ & $<\angle O Q$ \\
\hline 142 & 4.37 & 25,294 & 0.43 & $\begin{array}{l}2.06 \pm \\
0.318\end{array}$ & $\angle O O Q$ & $<\angle O Q$ & $\begin{array}{l}0.81 \pm \\
0.0243\end{array}$ & 4.34 & 22,075 & 0.57 & $<\angle O Q$ & $<\angle O Q$ & $\begin{array}{l}2.48 \pm \\
0.0744\end{array}$ & $<\angle O Q$ & 5.32 & 24,806 & 0.07 & $<\angle O Q$ & $\begin{array}{l}87.04 \pm \\
2.6112\end{array}$ & $<\angle O Q$ & $\begin{array}{c}110.29 \pm \\
3.3087\end{array}$ \\
\hline 143 & 6.71 & 21,061 & 0.21 & $\begin{array}{l}4.20 \pm \\
0.126\end{array}$ & $<\mathrm{LOQ}$ & $<\angle O Q$ & $\begin{array}{l}6.04 \pm \\
0.1812\end{array}$ & 6.19 & 23,627 & 0.24 & $<\angle O Q$ & $\begin{array}{l}1.26 \pm \\
0.0378\end{array}$ & $\begin{array}{l}11.58 \pm \\
0.3474\end{array}$ & $<\angle O Q$ & $\mid 6.60$ & 24,501 & 0.19 & $<\angle O Q$ & $\begin{array}{l}19.01 \pm \\
0.5703\end{array}$ & $<\angle O Q$ & $\begin{array}{l}34.47 \pm \\
1.0341\end{array}$ \\
\hline 145 & 7.12 & 23,018 & 0.23 & $\begin{array}{l}0.126 \\
4.13 \pm \\
0.1239\end{array}$ & $\angle \mathrm{LOQ}$ & $\angle \angle Q Q$ & $\frac{0.1812}{<L 0 Q}$ & 6.86 & 25,761 & 0.29 & $\angle L O Q$ & $\begin{array}{l}0.03 / 8 \\
<\mathrm{LOQ}\end{array}$ & $\begin{array}{c}0.344 \\
3.83 \pm \\
0.1149\end{array}$ & $\angle \angle O Q$ & 7.01 & 24,501 & 0.18 & $\angle \angle O Q$ & $\begin{array}{l}0.50303 \\
7.53 \\
0.2259\end{array}$ & $2.16 \pm 0.0648$ & $\begin{array}{l}1.0341 \\
<L O Q\end{array}$ \\
\hline 146 & 6.89 & 24,882 & 0.44 & $\begin{array}{l}0.86 \pm \\
0.0258\end{array}$ & $\angle L O Q$ & $\angle O Q$ & $<\angle O Q$ & & & & $\angle L O Q$ & $\angle L O Q$ & $\angle 0 Q$ & $\angle L O Q$ & & & & $\angle L O Q$ & $\angle L O Q$ & $\angle O O Q$ & $<\angle O Q$ \\
\hline 147 & 5.93 & 20,411 & 0.20 & $\begin{array}{l}4.65 \pm \\
0.1395\end{array}$ & $<\angle O Q$ & $\angle L Q$ & $<\angle O Q$ & 6.15 & 16,836 & 0.86 & $<\angle O Q$ & $\angle L Q$ & $\begin{array}{l}0.95 \pm \\
0.0285\end{array}$ & $<\angle O Q$ & 6.37 & 30,242 & 0.70 & $<\angle O Q$ & $\begin{array}{l}2.45 \pm \\
0.0735\end{array}$ & $1.11 \pm 0.0333$ & $\begin{array}{l}6.11 \pm \\
0.1833\end{array}$ \\
\hline 148 & 5.92 & 21,506 & 0.39 & $\begin{array}{l}2.56 \pm \\
0.0768 \\
\end{array}$ & $\angle \mathrm{LOQ}$ & $<\angle O Q$ & $<L O Q$ & & & & $<\mathrm{LOQ}$ & $<L Q Q$ & $\begin{array}{l}.0200 \\
L O Q\end{array}$ & $<\angle O Q$ & 6.46 & 31,747 & 1.26 & $<\angle O Q$ & $\begin{array}{c}0.06 \pm \\
0.0918\end{array}$ & $<\angle O Q$ & $\frac{1.1035}{<L Q Q}$ \\
\hline 149 & 5.93 & 18,579 & 0.25 & $\begin{array}{l}8.47 \pm \\
0.2541\end{array}$ & $\begin{array}{l}6.09 \pm \\
0.1827\end{array}$ & $<\angle O Q$ & $\begin{array}{l}1.23 \pm \\
0.0369\end{array}$ & & & & $<L O Q$ & $\angle L Q Q$ & $<\angle O Q$ & $<\angle O Q$ & 6.33 & 28,543 & 0.30 & $<\angle O Q$ & $\begin{array}{l}9.84 \pm \\
0.2952\end{array}$ & $<\angle O Q$ & $<\angle O Q$ \\
\hline 150 & 5.96 & 22,307 & 0.23 & $\begin{array}{l}1.68 \pm \\
0.0504\end{array}$ & $\angle L O Q$ & $\angle \mathrm{LOQ}$ & $<\angle O Q$ & 6.20 & 19,781 & 0.20 & $\angle L O Q$ & $\angle \angle O Q$ & $\begin{array}{l}15.02 \pm \\
0.4506\end{array}$ & $<\angle O Q$ & \begin{tabular}{|l|l|}
6.67 & \\
\end{tabular} & 33,737 & 1.03 & $\angle \angle O Q$ & $\begin{array}{l}3.52 \pm \\
0.1056\end{array}$ & $0.76 \pm 0.0228$ & $\begin{array}{l}4.00 \pm \\
0.1200\end{array}$ \\
\hline 156 & & & & $<\angle O Q$ & $<\mathrm{LOQ}$ & $<\angle O Q$ & $<\angle O Q$ & 9.33 & 17,269 & 0.37 & $\angle \angle O Q$ & $<\angle O Q$ & $\begin{array}{c}10.50 \pm \\
0.315\end{array}$ & $<\angle O Q$ & & & & $<\angle O Q$ & $<\angle O Q$ & $<\angle O Q$ & $<\angle O Q$ \\
\hline 160 & & & & $\angle L O Q$ & $\angle \mathrm{LOO}$ & $\angle L Q$ & $<\angle O Q$ & 5.25 & 25.989 & 0.79 & $<\angle 0 Q$ & $\begin{array}{l}1.11 \pm \\
0.0333\end{array}$ & 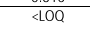 & $<\angle O Q$ & & & & $<\angle O Q$ & $\angle L Q$ & $\angle \angle O Q$ & $\angle\llcorner O Q$ \\
\hline 161 & 5.34 & 23,751 & 0.16 & $\begin{array}{l}1.09 \pm \\
0.0327\end{array}$ & $\angle \mathrm{LOQ}$ & $<\angle O Q$ & $<L O Q$ & & & & $<\angle O Q$ & $\frac{1.053}{\angle 0 Q}$ & $<L Q$ & $<L O Q$ & 5.79 & 18,625 & 0.81 & $<\angle O Q$ & $\begin{array}{l}5.08 \pm \\
0.1524\end{array}$ & $<\angle O Q$ & $\begin{array}{l}21.08 \pm \\
0.6324\end{array}$ \\
\hline
\end{tabular}

FI was used to find the pathways of these 114 proteins that were considered significantly enriched (FDR $<0.05$ ); the UniProt protein IDs were converted to gene symbols. Considering FDR $<0.05,35$ pathways were considered to be significantly enriched (Fig. 2), and the majority were related to the metabolism of amino acids and derivates (19 genes), glycogen storage diseases (13 genes), metabolism of carbohydrates (13 genes), biological oxidations (12 genes) and glucose metabolism (12 genes).

\subsubsection{Amino acid metabolism}

Carbamoyl phosphate synthase [ammonia] (CPS1) is ATP- and nucleotide-binding, and it is involved in the urea cycle (controls the entry of ammonia into the urea cycle). In the literature, there are no reports that this enzyme has a specific metal-binding property, but there is a report that it can be inactivated by a mixed-function oxidation binding a divalent metal and generally requiring a nucleotide [26]. However, in this work, the most important find was in the DM1 + I group, $\mathrm{Cu}$ and $\mathrm{Zn}$ were found; as these elements are divalent, it may be inferred that binding with $\mathrm{Cu}$ and $\mathrm{Zn}$ can cause the inactivation of this enzyme in the DM1+I group associated with the control of hyperglycemia by insulin and a decrease in the production of ammonia. Ornithine carbamoyltransferase (OTC) is another enzyme involved in the urea cycle (it catalyzes the formation of L-citrulline from carbamoyl phosphate and L-ornithine). A study reported that this enzyme is regulated by $\mathrm{Zn}$ in two different ways: as an allosteric cofactor of the substrate- bound enzyme (site-site interactions) and by inducing inactivation by a slow, tight-binding inhibitor of the free enzyme [27]. The cysteinyl residue at position 273 of the enzyme has been identified as a metal ligand [28]. In this study, the presence of $\mathrm{Cu}$ was found in the $\mathrm{C}$ group and $\mathrm{Cu}, \mathrm{Mg}$, Se and $\mathrm{Zn}$ were found in the $\mathrm{DM} 1+\mathrm{I}$ group. $\mathrm{Cu}, \mathrm{Mg}$ and Se have not yet been reported as binding with OTC; it can be suggested that in DM1 + I inactivation of this enzyme by hyperglycemia control is induced by insulin. Arginase-1 (AGR1) was found in spot ID 79, and sorbitol dehydrogenase (SORD) was also found in this spot. AGR1 is a binuclear manganese (Mn) metalloenzyme that catalyzes the hydrolysis of arginine to ornithine and urea [29], and SORD is a Zn metalloenzyme (a tetramer containing one $\mathrm{Zn}$ atom/subunit) involved in the catalysis of sorbitol/fructose interconversion [30]. Some alterations in this conversion are associated in diabetes with cataract formation, neuropathy, retinopathy and nephropathy [30]. The results showed in spot 79, the presence of $\mathrm{Zn}$ in $\mathrm{C}$, Se in DM1 and $\mathrm{Cu}, \mathrm{Mg}$ and $\mathrm{Zn}$ in DM1+I. No other previous reports have shown that ARG protein binds with $\mathrm{Cu}, \mathrm{Mg}$ and $\mathrm{Zn}$, and SORD with $\mathrm{Cu}$ and $\mathrm{Mg}$. Beta-ureidopropionase (UPB1), 4-hydroxyphenylpyruvate dioxygenase (HPD) and fumarylacetoacetase (FAH) were identified in spot 77 , where the presence of $\mathrm{Mg}$ was found in C, Se in DM1 and $\mathrm{Cu}, \mathrm{Se}, \mathrm{Mg}$ and $\mathrm{Zn}$ in DM1 + I. UPB1 is a metalloenzyme that binds two $\mathrm{Zn}^{2+}$ ions per subunit [31], HPD is a metalloenzyme that binds one Fe cation per subunit [32] and $\mathrm{FAH}$ binds with $\mathrm{Ca}^{2+}$ and $\mathrm{Mg}^{2+}$ [33]. Other proteins associated with this metabolism such as S-adenosylmethionine synthase 
Table 2

\begin{tabular}{|c|c|c|c|c|c|c|c|c|c|c|}
\hline Spot ID & Protein entry & Protein & Score & $\begin{array}{l}\text { pI (theo- } \\
\text { retical) }\end{array}$ & $\begin{array}{l}\text { Mw (Da, } \\
\text { theoretical) }\end{array}$ & Peptides & Coverage (\%) & Biological process & $\begin{array}{l}\text { Metabolism } \\
\text { associated }\end{array}$ & $\begin{array}{l}\mathrm{Cu}, \mathrm{Mg} \text {, Se and } \mathrm{Zn} \\
\text { presence }\end{array}$ \\
\hline 4 & P07756 & $\begin{array}{l}\text { Carbamoyl-phosphate synthase } \\
\text { [ammonia]_ mitochondrial } \\
\text { OS = Rattus norvegicus } \mathrm{GN}=\text { Cps } 1 \\
\mathrm{PE}=1 \mathrm{SV}=1\end{array}$ & 653 & 6.33 & 164,580 & 13 & 10.95 & Urea cycle & $\begin{array}{l}\text { Amino-acid } \\
\text { metabolism }\end{array}$ & $\begin{array}{l}\mathrm{DM} 1=\mathrm{Se} ; \mathrm{DM} 1+\mathrm{I}=\mathrm{Cu} \\
\text { and } \mathrm{Mg}\end{array}$ \\
\hline 8 & P70498 & Phospholipase D2 (GN = Pld2) & 131 & 7.44 & 106,037 & 84 & 1.82 & $\begin{array}{l}\text { Response to hydrogen } \\
\text { peroxide, hypoxia, organic } \\
\text { cyclic compounds and } \\
\text { peptide hormone }\end{array}$ & Lipid metabolism & $\begin{array}{l}\text { DM1 }=\text { Se and } \mathrm{Zn} ; \\
\text { DM1 }+\mathrm{I}=\mathrm{Cu} \text { and } \mathrm{Mg}\end{array}$ \\
\hline 10 & 088600 & $\begin{array}{l}\text { Heat shock } 70 \text { kDa protein } 4 \\
\mathrm{OS}=\mathrm{Rattus} \text { norvegicus } \mathrm{GN}=\mathrm{Hspa} 4 \\
\mathrm{PE}=1 \mathrm{SV}=1\end{array}$ & 94 & 5.12 & 94,057 & 74 & 7.14 & Stress response & Chaperone & $\mathrm{DM} 1+\mathrm{I}=\mathrm{Cu}$ and $\mathrm{Se}$ \\
\hline 11 & P50475 & $\begin{array}{l}\text { Alanine-tRNA ligase } \_ \text {cytoplasmic } \\
\mathrm{OS}=\text { Rattus norvegicus } \mathrm{GN}=\text { Aars } \\
\mathrm{PE}=1 \mathrm{SV}=3\end{array}$ & 177 & 5.41 & 106,790 & 82 & 10.74 & Protein biosynthesis & Nucleotide & $\mathrm{DM} 1+\mathrm{I}=\mathrm{Cu}$ and $\mathrm{Se}$ \\
\hline 14 & Q63060 & $\begin{array}{l}\text { Glycerol kinase } \mathrm{OS}=\text { Rattus } \\
\text { norvegicus } \mathrm{GN}=\mathrm{Gk} \mathrm{PE}=2 \mathrm{SV}=1\end{array}$ & 717 & 5.49 & 57,477 & 44 & 12.21 & $\begin{array}{l}\text { glycerol degradation via } \\
\text { glycerol kinase pathway }\end{array}$ & $\begin{array}{l}\text { Glycerol } \\
\text { metabolism }\end{array}$ & $\begin{array}{l}\text { DM1 }=\text { Se and } \mathrm{Zn} ; \\
\text { DM1 + I = Cu and Mg }\end{array}$ \\
\hline 15 & P28037 & $\begin{array}{l}\text { Cytosolic } \\
10 \text {-formyltetrahydrofolate } \\
\text { dehydrogenase OS = Rattus } \\
\text { norvegicus GN = Aldh111 PE=1 } \\
\text { SV = } 3\end{array}$ & 1633 & 6.15 & 101,440 & 79 & 21.51 & Oxireductase & $\begin{array}{l}\text { Choline and glycine } \\
\text { metabolism }\end{array}$ & $\begin{array}{l}\mathrm{DM} 1=\mathrm{Se} \text { and } \mathrm{Zn} ; \\
\mathrm{DM} 1+\mathrm{I}=\mathrm{Cu}, \mathrm{Mg} \text { and } \mathrm{Zn}\end{array}$ \\
\hline 16 & P28037 & $\begin{array}{l}\text { Cytosolic } \\
\text { 10-formyltetrahydrofolate } \\
\text { dehydrogenase OS= Rattus } \\
\text { norvegicus GN = Aldh111 PE = } 1 \\
\mathrm{SV}=3\end{array}$ & 1633 & 6.15 & 101,440 & 79 & 24.72 & Oxireductase & $\begin{array}{l}\text { Choline and glycine } \\
\text { metabolism }\end{array}$ & $\begin{array}{l}\text { DM1 }=\text { Se and } Z n ; \\
\text { DM1 }+\mathrm{I}=\mathrm{Cu} \text { and } \mathrm{Zn}\end{array}$ \\
\hline 17 & Q64380 & $\begin{array}{l}\text { Sarcosine dehydrogenase } \\
\text { mitochondrial OS = Rattus } \\
\text { norvegicus } G N=\text { Sardh } P E=1 \mathrm{SV}=2\end{array}$ & 1514 & 6.58 & 43,045 & 31 & 5.51 & Kinase, transferase & $\begin{array}{l}\text { Creatine } \\
\text { metabolism }\end{array}$ & $\begin{array}{l}\mathrm{DM} 1=\mathrm{Se} ; \mathrm{DM} 1+\mathrm{I}=\mathrm{Cu} \\
\text { Mg and } \mathrm{Zn}\end{array}$ \\
\hline 20 & P09034 & $\begin{array}{l}\text { Argininosuccinate synthase } \\
\mathrm{OS}=\mathrm{Rattus} \text { norvegicus } \mathrm{GN}=\mathrm{Ass} 1 \\
\mathrm{PE}=2 \mathrm{SV}=1\end{array}$ & 2849 & 7.63 & 46,496 & 33 & 36.65 & Urea cycle & $\begin{array}{l}\text { Amino-acid } \\
\text { metabolism }\end{array}$ & $\begin{array}{l}\mathrm{DM} 1=\mathrm{Se} ; \mathrm{DM} 1+\mathrm{I}=\mathrm{Cu} \\
\text { and } \mathrm{Mg}\end{array}$ \\
\hline 21 & Q02253 & $\begin{array}{l}\text { Methylmalonate-semialdehyde } \\
\text { dehydrogenase [acylating] } \\
\text { mitochondrial OS= Rattus } \\
\text { norvegicus GN = Aldh6a1 PE =1 } \\
\text { SV=1 }\end{array}$ & 7429 & 8.47 & 57,808 & 44 & 35.14 & Oxidoreductase & $\begin{array}{l}\text { Valine and } \\
\text { pyrimidine } \\
\text { metabolism }\end{array}$ & $\begin{array}{l}\mathrm{C}=\mathrm{Mg} ; \mathrm{DM} 1=\mathrm{Se} \\
\mathrm{DM} 1+\mathrm{I}=\mathrm{Cu} \text { and } \mathrm{Se}\end{array}$ \\
\hline 22 & O09171 & $\begin{array}{l}\text { Betaine-homocysteine } \\
\text { S-methyltransferase } 1 \mathrm{OS}=\text { Rattus } \\
\text { norvegicus } \mathrm{GN}=\mathrm{Bhmt} \mathrm{PE}=1 \mathrm{SV}=1\end{array}$ & 2238 & 8 & 39,929 & 29 & 6.06 & $\begin{array}{l}\text { Betaine-homocysteine } \\
\text { S-methyltransferase } \\
\text { activity, } \\
\text { S-adenosylmethionine- } \\
\text { homocysteine } \\
\text { S-methyltransferase } \\
\text { activity and } \\
\text { S-methylmethionine- } \\
\text { homocysteine } \\
\text { S-methyltransferase } \\
\text { activity }\end{array}$ & $\begin{array}{l}\text { Mehionine } \\
\text { metabolism }\end{array}$ & $\mathrm{DM} 1+\mathrm{I}=\mathrm{Cu}, \mathrm{Mg}$ and $\mathrm{Zn}$ \\
\hline \multirow[t]{2}{*}{24} & P12346 & $\begin{array}{l}\text { Serotransferrin } \mathrm{OS}=\text { Rattus } \\
\text { norvegicus } \mathrm{GN}=\mathrm{Tf} \mathrm{PE}=1 \mathrm{SV}=3\end{array}$ & 1104 & 7.14 & 76,395 & 65 & 14.76 & $\begin{array}{l}\text { ferric iron transmembrane } \\
\text { transporter activit }\end{array}$ & Transport & $\mathrm{DM} 1=\mathrm{Se} ; \mathrm{DM} 1+\mathrm{I}=\mathrm{Cu}$ \\
\hline & Q5XHY5 & $\begin{array}{l}\text { Threonine-tRNA ligase } \\
\text { cytoplasmic } \mathrm{OS}=\mathrm{Rattus} \text { norvegicus } \\
\mathrm{GN}=\text { Tars } \mathrm{PE}=2 \mathrm{SV}=1\end{array}$ & 935 & 6.5 & 80,576 & 53 & 15.11 & Protein biosynthesis & $\begin{array}{l}\text { Amino-acid } \\
\text { metabolism }\end{array}$ & \\
\hline 27 & 035244 & $\begin{array}{l}\text { Peroxiredoxin }-6 \text { OS }=\text { Rattus } \\
\text { norvegicus } \mathrm{GN}=\operatorname{Prdx} 6 \mathrm{PE}=1 \mathrm{SV}=3\end{array}$ & 6304 & 7.14 & 76,395 & 65 & 16.76 & redox regulation & Oxidative stress & $\mathrm{DM} 1+\mathrm{I}=\mathrm{Cu}$ and $\mathrm{Mg}$ \\
\hline
\end{tabular}




\begin{tabular}{|c|c|c|c|c|c|c|c|c|c|c|}
\hline & P12346 & $\begin{array}{l}\text { Serotransferrin } \mathrm{OS}=\text { Rattus } \\
\text { norvegicus } \mathrm{GN}=\mathrm{Tf} \mathrm{PE}=1 \mathrm{SV}=3\end{array}$ & 709 & 7.14 & 76,395 & 55 & 14.49 & $\begin{array}{l}\text { ferric iron transmembrane } \\
\text { transporter activit }\end{array}$ & Transport & \\
\hline 28 & Q9ER34 & $\begin{array}{l}\text { Aconitate hydratase } \\
\text { mitochondrial } \mathrm{OS}=\text { Rattus } \\
\text { norvegicus } \mathrm{GN}=\mathrm{AcO} 2 \mathrm{PE}=1 \mathrm{SV}=2\end{array}$ & 245 & 5.97 & 73,858 & 69 & 19 & $\begin{array}{l}\text { Response to toxic } \\
\text { substance }\end{array}$ & Chaperone & $\begin{array}{l}\text { DM1 = Se and Zn; } \\
\text { DM1 }+\mathrm{I}=\mathrm{Cu}\end{array}$ \\
\hline \multirow[t]{2}{*}{31} & P34058 & $\begin{array}{l}\text { Heat shock protein HSP 90-beta } \\
\mathrm{OS}=\text { Rattus norvegicus } \\
\mathrm{GN}=\mathrm{Hsp} 90 \mathrm{ab} 1 \mathrm{PE}=1 \mathrm{SV}=4\end{array}$ & 3813 & 4.96 & 83,281 & 67 & 30.66 & $\begin{array}{l}\text { chaperone, cellular } \\
\text { response to interleukin- } 4 \text {, } \\
\text { negative regulation of } \\
\text { neuron apoptotic process }\end{array}$ & Chaperone & $\begin{array}{l}\mathrm{DM} 1=\mathrm{Se} ; \mathrm{DM} 1+\mathrm{I}=\mathrm{Mg} \\
\text { and Se }\end{array}$ \\
\hline & P82995 & $\begin{array}{l}\text { Heat shock protein HSP 90-alpha } \\
\text { OS }=\text { Rattus norvegicus } \\
\text { GN=Hsp90aa } 1 \mathrm{PE}=1 \mathrm{SV}=3\end{array}$ & 2081 & 4.93 & 84,815 & 91 & 18.14 & Stress response & Chaperone & \\
\hline 32 & P20059 & $\begin{array}{l}\text { Hemopexin OS= Rattus norvegicus } \\
G N=H p x P E=1 S V=3\end{array}$ & 182 & 7.58 & 51,351 & 36 & 15.65 & $\begin{array}{l}\text { cellular iron ion } \\
\text { homeostasis }\end{array}$ & Transport & $\mathrm{DM} 1+\mathrm{I}=\mathrm{Cu}$ and $\mathrm{Mg}$ \\
\hline \multirow[t]{2}{*}{33} & P48721 & $\begin{array}{l}\text { Stress-70 protein_ } \text { mitochondrial } \\
\mathrm{OS}=\mathrm{Rattus} \text { norvegicus } \mathrm{GN}=\mathrm{Hspa} 9 \\
\mathrm{PE}=1 \mathrm{SV}=3\end{array}$ & 3792 & 5.37 & 70,871 & 50 & 17.03 & $\begin{array}{l}\text { mRNA processing, mRNA } \\
\text { splicing, stress response, } \\
\text { transcription, transcription } \\
\text { regulation }\end{array}$ & Chaperone & $\begin{array}{l}\mathrm{DM} 1+\mathrm{I}=\mathrm{Cu}, \mathrm{Mg}, \mathrm{Se} \\
\text { and } \mathrm{Zn}\end{array}$ \\
\hline & P63018 & $\begin{array}{l}\text { Heat shock cognate } 71 \mathrm{kDa} \text { protein } \\
\mathrm{OS}=\mathrm{Rattus} \text { norvegicus } \mathrm{GN}=\mathrm{Hspa} 8 \\
\mathrm{PE}=1 \mathrm{SV}=1\end{array}$ & 93 & 5.50 & 69,642 & 57 & 17.68 & Stress response & Chaperone & \\
\hline 35 & P02793 & $\begin{array}{l}\text { Ferritin light chain } 1 \mathrm{OS}=\text { Rattus } \\
\text { norvegicus } \mathrm{GN}=\mathrm{Ftl} 1 \mathrm{PE}=1 \mathrm{SV}=3\end{array}$ & 220 & 5.98 & 20,749 & 16 & 27.87 & Iron storage & Other & $\begin{array}{l}\mathrm{DM} 1=\mathrm{Se} \text { and } \mathrm{Zn} \\
\mathrm{DM} 1+\mathrm{I}=\mathrm{Cu} \text { and } \mathrm{Se}\end{array}$ \\
\hline 36 & P02770 & $\begin{array}{l}\text { Serum albumin } \mathrm{OS}=\mathrm{RattuS} \\
\text { norvegicus } \mathrm{GN}=\mathrm{Alb} \mathrm{PE}=1 \mathrm{SV}=2\end{array}$ & 3023 & 6.09 & 68,731 & 50 & 20.07 & Transport & Other & $\begin{array}{l}\mathrm{DM} 1=\mathrm{Se} ; \mathrm{DM} 1+\mathrm{I}=\mathrm{Cu} \text {, } \\
\mathrm{Mg} \text { and } \mathrm{Zn}\end{array}$ \\
\hline 37 & P14882 & $\begin{array}{l}\text { Propionyl-CoA carboxylase alpha } \\
\text { chain_mitochondrial } \mathrm{OS}=\mathrm{Rattus} \\
\text { norvegicus } \mathrm{GN}=\text { Pcca } \mathrm{PE}=1 \mathrm{SV}=3\end{array}$ & 531 & 7.6 & 81,623 & 60 & 16.01 & $\begin{array}{l}\text { cellular amino acid and } \\
\text { fatty acid catabolic process }\end{array}$ & $\begin{array}{l}\text { Amino-acid } \\
\text { metabolism }\end{array}$ & $\mathrm{C}=\mathrm{Cu}$ \\
\hline \multirow[t]{4}{*}{$38-39$} & P07379 & $\begin{array}{l}\text { Phosphoenolpyruvate } \\
\text { carboxykinase_cytosolic [GTP] } \\
\text { OS = Rattus norvegicus GN = Pck1 } \\
\text { PE }=1 \mathrm{SV}=1\end{array}$ & 2569 & 6.75 & 71,615 & 47 & 10.52 & Tricarboxylic acid cycle & $\begin{array}{l}\text { Carbohydrate } \\
\text { metabolism }\end{array}$ & $\begin{array}{l}\mathrm{DM} 1=\mathrm{Se} \text { and } \mathrm{Zn} ; \\
\mathrm{DM} 1+\mathrm{I}=\mathrm{Cu}, \mathrm{Mg} \text { and Se }\end{array}$ \\
\hline & Q920L2 & $\begin{array}{l}\text { Succinate dehydrogenase } \\
\text { [ubiquinone] flavoprotein subunit_ } \\
\text { mitochondrial OS= Rattus } \\
\text { norvegicus GN = Sdha PE = } 1 \text { SV= } 1\end{array}$ & 633 & 6.45 & 62,200 & 46 & 17.94 & Glycolysis & $\begin{array}{l}\text { Carbohydrate } \\
\text { metabolism }\end{array}$ & \\
\hline & P12928 & $\begin{array}{l}\text { Pyruvate kinase PKLR OS }=\text { Rattus } \\
\text { norvegicus } \mathrm{GN}=\mathrm{Pklr} \mathrm{PE}=2 \mathrm{SV}=2\end{array}$ & 107 & 6.23 & 60,647 & 49 & 9.54 & Toxin transport & Chaperone & \\
\hline & Q6P502 & $\begin{array}{l}\text { T-complex protein } 1 \text { subunit } \\
\text { gamma } \mathrm{OS}=\mathrm{Rattus} \text { norvegicus } \\
\mathrm{GN}=\mathrm{Cct} 3 \mathrm{PE}=1 \mathrm{SV}=1\end{array}$ & 98 & 5.07 & 72,347 & 52 & 26.91 & Stress response & Chaperone & \\
\hline \multirow[t]{5}{*}{41} & P06761 & $\begin{array}{l}78 \mathrm{kDa} \text { glucose-regulated protein } \\
\mathrm{OS}=\mathrm{Rattus} \text { norvegicus } \mathrm{GN}=\mathrm{Hspa} 5 \\
\mathrm{PE}=1 \mathrm{SV}=1\end{array}$ & 8726 & 5.91 & 70,549 & 51 & 16.54 & Stress response & Chaperone & $\begin{array}{l}\mathrm{DM} 1=\mathrm{Se} ; \mathrm{DM} 1+\mathrm{I}=\mathrm{Cu} \\
\text { and Mg }\end{array}$ \\
\hline & P55063 & $\begin{array}{l}\text { Heat shock } 70 \mathrm{kDa} \text { protein } 1 \text {-like } \\
\text { OS }=\text { Rattus norvegicus } \\
\text { GN=Hspa1 L PE }=2 \mathrm{SV}=2\end{array}$ & 932 & 5.91 & 70,550 & 48 & 9.83 & Stress response & Chaperone & \\
\hline & Q07439 & $\begin{array}{l}\text { Heat shock } 70 \mathrm{kDa} \text { protein } 1 \mathrm{~A} / 1 \mathrm{~B} \\
\mathrm{OS}=\mathrm{Rattus} \text { norvegicus } \mathrm{GN}=\mathrm{Hspa} 1 \mathrm{a} \\
\mathrm{PE}=2 \mathrm{SV}=2\end{array}$ & 897 & 5.37 & 70,871 & 50 & 6.19 & Stress response & Chaperone & \\
\hline & P63018 & $\begin{array}{l}\text { Heat shock cognate } 71 \mathrm{kDa} \text { protein } \\
\mathrm{OS}=\mathrm{Rattus} \text { norvegicus } \mathrm{GN}=\mathrm{Hspa} 8 \\
\mathrm{PE}=1 \mathrm{SV}=1\end{array}$ & 894 & 5.50 & 69,642 & 50 & 6.32 & Stress response & Chaperone & \\
\hline & P14659 & $\begin{array}{l}\text { Heat shock-related } 70 \mathrm{kDa} \text { protein } \\
2 \mathrm{OS}=\mathrm{Rattus} \text { norvegicus } \\
\mathrm{GN}=\mathrm{Hspa} 2 \mathrm{PE}=1 \mathrm{SV}=2\end{array}$ & 894 & 5.37 & 70,871 & 50 & 40.09 & Stress response & Chaperone & \\
\hline
\end{tabular}




\begin{tabular}{|c|c|c|c|c|c|c|c|c|c|c|}
\hline Spot ID & Protein entry & Protein & Score & $\begin{array}{l}\mathrm{pI}(\text { theo- } \\
\text { retical) }\end{array}$ & $\begin{array}{l}\mathrm{Mw}(\mathrm{Da}, \\
\text { theoretical })\end{array}$ & Peptides & Coverage (\%) & Biological process & $\begin{array}{l}\text { Metabolism } \\
\text { associated }\end{array}$ & $\begin{array}{l}\mathrm{Cu}, \mathrm{Mg} \text {, Se and } \mathrm{Zn} \\
\text { presence }\end{array}$ \\
\hline \multirow[t]{4}{*}{42} & P63018 & $\begin{array}{l}\text { Heat shock cognate } 71 \mathrm{kDa} \text { protein } \\
\mathrm{OS}=\mathrm{Rattus} \text { norvegicus } \mathrm{GN}=\mathrm{Hspa} 8 \\
\mathrm{PE}=1 \mathrm{SV}=1\end{array}$ & 7256 & 5.50 & 69,642 & 50 & 12.64 & Stress response & Chaperone & $\begin{array}{l}\text { DM1 = Se; DM1 + I=Cu, } \\
\text { Se and Zn }\end{array}$ \\
\hline & Q07439 & $\begin{array}{l}\text { Heat shock } 70 \mathrm{kDa} \text { protein } 1 \mathrm{~A} / 1 \mathrm{~B} \\
\mathrm{OS}=\mathrm{Rattus} \text { norvegicus } \mathrm{GN}=\mathrm{Hspa} 1 \mathrm{a} \\
\mathrm{PE}=2 \mathrm{SV}=2\end{array}$ & 3042 & 5.91 & 70,550 & 49 & 19.66 & Stress response & Chaperone & \\
\hline & P14659 & $\begin{array}{l}\text { Heat shock-related } 70 \mathrm{kDa} \text { protein } \\
2 \mathrm{OS}=\text { Rattus norvegicus } \\
\mathrm{GN}=\mathrm{Hspa} 2 \mathrm{PE}=1 \mathrm{SV}=2\end{array}$ & 2938 & 5.91 & 70,549 & 51 & 12.64 & Stress response & Chaperone & \\
\hline & P55063 & $\begin{array}{l}\text { Heat shock } 70 \text { kDa protein } 1 \text {-like } \\
\mathrm{OS}=\text { Rattus norvegicus } \\
\mathrm{GN}=\mathrm{H} \text { spa1 } \mathrm{LE}=2 \mathrm{SV}=2\end{array}$ & 2128 & 5.07 & 72,347 & 52 & 5.5 & Stress response & Chaperone & \\
\hline 43 & P38652 & $\begin{array}{l}\text { Phosphoglucomutase }-1 \mathrm{OS}=\text { Rattus } \\
\text { norvegicus } \mathrm{GN}=\mathrm{Pgm} 1 \mathrm{PE}=1 \mathrm{SV}=2\end{array}$ & 4463 & 6.3 & 61,403 & 44 & 37.01 & Glycolysis/gluconeogenesis & $\begin{array}{l}\text { Carbohydrate } \\
\text { metabolism }\end{array}$ & $\mathrm{DM} 1+\mathrm{I}=\mathrm{Cu}, \mathrm{Mg}$ and Se \\
\hline \multirow[t]{9}{*}{44} & P04762 & $\begin{array}{l}\text { Catalase } \mathrm{OS}=\text { Rattus norvegicus } \\
\mathrm{GN}=\text { Cat } \mathrm{PE}=1 \mathrm{SV}=3\end{array}$ & 657 & 7.07 & 59,757 & 42 & 21.14 & $\begin{array}{l}\text { Response to reactive } \\
\text { oxygen species }\end{array}$ & Oxidative stress & $\mathrm{C}=\mathrm{Mg}$ \\
\hline & $\mathrm{P} 0 \mathrm{C} 2 \times 9$ & $\begin{array}{l}\text { Delta-1-pyrroline-5-carboxylate } \\
\text { dehydrogenase_ mitochondrial } \\
\text { OS = Rattus norvegicus } \\
\text { GN = Aldh4a1 } \mathrm{PE}=1 \mathrm{SV}=1\end{array}$ & 627 & 7.13 & 61,869 & 33 & 30.10 & Oxidoreductase & Proline metabolism & \\
\hline & P38652 & $\begin{array}{l}\text { Phosphoglucomutase }-1 \mathrm{OS}=\text { Rattus } \\
\text { norvegicus } \mathrm{GN}=\mathrm{Pgm} 1 \mathrm{PE}=1 \mathrm{SV}=2\end{array}$ & 590 & 6.3 & 61,403 & 44 & 17.79 & $\begin{array}{l}\text { glycolysis/gluconeogenesis } \\
\text { pathway }\end{array}$ & $\begin{array}{l}\text { Carbohydrate } \\
\text { metabolism }\end{array}$ & \\
\hline & P32232 & $\begin{array}{l}\text { Cystathionine beta-synthase } \\
\mathrm{OS}=\mathrm{Rattus} \text { norvegicus } \mathrm{GN}=\mathrm{Cbs} \\
\mathrm{PE}=1 \mathrm{SV}=3\end{array}$ & 453 & 6.29 & 62,308 & 54 & 19.07 & $\begin{array}{l}\text { Carboxylic ester hydrolase } \\
\text { activity }\end{array}$ & Lipid metabolism & \\
\hline & Q64573 & $\begin{array}{l}\text { Liver carboxylesterase } 4 \\
\mathrm{OS}=\text { Rattus norvegicus } \mathrm{PE}=2 \mathrm{SV}=2\end{array}$ & 426 & 6.25 & 62,495 & 57 & 11.23 & $\begin{array}{l}\text { Carboxylic ester hydrolase } \\
\text { activity }\end{array}$ & Lipid metabolism & \\
\hline & Q63010 & $\begin{array}{l}\text { Liver carboxylesterase } B-1 \\
O S=\text { Rattus norvegicus } P E=1 \quad S V=1\end{array}$ & 372 & 6.10 & 62,147 & 36 & 11.68 & $\begin{array}{l}\text { Carboxylic ester hydrolase } \\
\text { activity }\end{array}$ & Lipid metabolism & \\
\hline & P16303 & $\begin{array}{l}\text { Carboxylesterase } 1 \mathrm{D} \text { OS }=\text { Rattus } \\
\text { norvegicus } \mathrm{GN}=\operatorname{Ces} 1 \mathrm{~d} \mathrm{PE}=1 \mathrm{SV}=2\end{array}$ & 345 & 5.64 & 61,715 & 39 & 5.35 & $\begin{array}{l}\text { Carboxylic ester hydrolase } \\
\text { activity }\end{array}$ & Lipid metabolism & \\
\hline & Q63108 & $\begin{array}{l}\text { Carboxylesterase } 1 \mathrm{E} \mathrm{OS}=\text { Rattus } \\
\text { norvegicus } \mathrm{GN}=\mathrm{Ces} 1 \mathrm{e} \mathrm{PE}=2 \mathrm{SV}=1\end{array}$ & 305 & 6.23 & 60,647 & 49 & 11.01 & Toxin transport & Chaperone & \\
\hline & Q6P502 & $\begin{array}{l}\text { T-complex protein } 1 \text { subunit } \\
\text { gamma OS = Rattus norvegicus } \\
\mathrm{GN}=\text { Cct3 } \mathrm{PE}=1 \mathrm{SV}=1\end{array}$ & 199 & 6.45 & 62,200 & 46 & 14.98 & Glycolysis & $\begin{array}{l}\text { Carbohydrate } \\
\text { metabolism }\end{array}$ & \\
\hline \multirow[t]{2}{*}{45} & P04762 & $\begin{array}{l}\text { Catalase } \mathrm{OS}=\text { Rattus norvegicus } \\
\mathrm{GN}=\mathrm{Cat} \mathrm{PE}=1 \mathrm{SV}=3\end{array}$ & 8595 & 7.07 & 59.757 & 42 & 21.49 & $\begin{array}{l}\text { Response to reactive } \\
\text { oxygen species }\end{array}$ & Oxidative stress & $\begin{array}{l}\mathrm{DM} 1=\mathrm{Se} ; \mathrm{DM} 1+\mathrm{I}=\mathrm{Cu} \text {, } \\
\mathrm{Mg} \text { and } \mathrm{Zn}\end{array}$ \\
\hline & $\mathrm{POC} 2 \times 9$ & 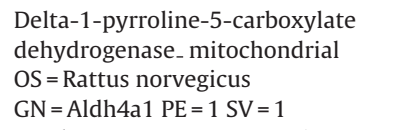 & 2270 & 7.13 & 61.849 & 46 & 33.78 & Oxidoreductase & Proline metabolism & \\
\hline \multirow[t]{2}{*}{46} & P04762 & $\begin{array}{l}\text { Catalase } \mathrm{OS}=\text { Rattus norvegicus } \\
\mathrm{GN}=\text { Cat } \mathrm{PE}=1 \mathrm{SV}=3\end{array}$ & 4785 & 7 & 66,093 & 42 & 20.43 & $\begin{array}{l}\text { Glutamate and proline } \\
\text { biosynthetic process }\end{array}$ & Proline metabolism & $\begin{array}{l}\mathrm{C}=\mathrm{Se}, \mathrm{DM} 1=\mathrm{Se} \text { and } \mathrm{Zn} ; \\
\mathrm{DM} 1+\mathrm{I}=\mathrm{Cu}, \mathrm{Mg} \text { and } \mathrm{Se}\end{array}$ \\
\hline & $\mathrm{POC} 2 \times 9$ & $\begin{array}{l}\text { Delta-1-pyrroline-5-carboxylate } \\
\text { dehydrogenase_mitochondrial } \\
\text { OS = Rattus norvegicus } \\
\text { GN = Aldh4a1 } \mathrm{PE}=1 \mathrm{SV}=1\end{array}$ & 1043 & 7.13 & 61.849 & 20 & 24.57 & Oxidoreductase & Proline metabolism & \\
\hline 47 & P13255 & $\begin{array}{l}\text { Glycine N-methyltransferase } \\
\mathrm{OS}=\mathrm{Rattus} \text { norvegicus } \mathrm{GN}=\mathrm{Gnmt} \\
\mathrm{PE}=1 \mathrm{SV}=2\end{array}$ & 12867 & 5.79 & 58,914 & 46 & 36.97 & Lyase, Transferase & $\begin{array}{l}\text { Histidine } \\
\text { metabolism }\end{array}$ & $\begin{array}{l}\text { DM1 = Se; DM1 + I = Cu, } \\
\text { Mg, Se and Zn }\end{array}$ \\
\hline 49 & P00564 & $\begin{array}{l}\text { Creatine kinase } \mathrm{M} \text {-type } \mathrm{OS}=\text { Rattus } \\
\text { norvegicus } \mathrm{GN}=\mathrm{Ckm} \mathrm{PE}=1 \mathrm{SV}=2\end{array}$ & 63 & 6.58 & 43,045 & 31 & 5.51 & $\begin{array}{l}\text { phosphocreatine } \\
\text { biosynthetic process, } \\
\text { response to heat }\end{array}$ & Other & $\begin{array}{l}\mathrm{DM} 1=\mathrm{Se} ; \mathrm{DM} 1+\mathrm{I}=\mathrm{Cu} \text {, } \\
\text { Mg and Se }\end{array}$ \\
\hline
\end{tabular}




\section{Q6P9T8} norvegicus $\mathrm{CN}=\mathrm{T}$

$$
\mathrm{SV}=1
$$

56

P69897 Tubulin beta- 5 chain OS $=$ Rattus

norvegicus $\mathrm{GN}=$ Tubb5 $\mathrm{PE}=1 \mathrm{SV}=1$

Formimidoyltransferase-

cyclodeaminase $\mathrm{OS}=$ Rattus

norvegicus $\mathrm{GN}=\mathrm{Ftcd} \mathrm{PE}=1 \mathrm{SV}=4$

P11598

$\mathrm{PE}=1 \mathrm{SV}=2$

Q07116 Sulfite oxidase_ mitochondrial $\mathrm{OS}=$ Rattus norvegicus $\mathrm{GN}=$ Suox $\mathrm{PE}=1 \mathrm{SV}=2$

60

Q63150 Dihydropyrimidinase OS $=$ Rattus

norvegicus $\mathrm{GN}=$ Dpys $\mathrm{PE}=1 \mathrm{SV}=2$

P70619

Glutathione reductase (Fragment) $\mathrm{OS}=$ Rattus norvegicus $\mathrm{GN}=\mathrm{Gsr}$ $\mathrm{PE}=2 \mathrm{SV}=2$

P10719

mitochondrial OS $=$ Rattus

norvegicus $\mathrm{GN}=\mathrm{Atp} 5 \mathrm{~b} \mathrm{PE}=1 \mathrm{SV}=2$

Q6308

Q8VIF7

$\mathrm{PE}=1 \mathrm{SV}=2$

67

P04764 Alpha-enolase OS = Rattus

P15429 Beta-enolase OS $=$ Rattus
norvegicus GN $=$ Eno3 PE $=1 \mathrm{SV}=3$

Gamma-enolase $\mathrm{OS}=$ Rattus

norvegicus $\mathrm{GN}=\mathrm{Eno} 2 \mathrm{PE}=1 \mathrm{SV}=2$

4-trimethylaminobutyraldehyde

dehydrogenase OS = Rattus

norvegicus $\mathrm{GN}=$ Aldh9a1 $\mathrm{PE}=1$

$\mathrm{SV}=1$

P25409 Alanine aminotransferase 1

$\mathrm{OS}=$ Rattus norvegicus $\mathrm{GN}=\mathrm{Gpt}$ $\mathrm{PE}=1 \mathrm{SV}=2$

norvegicus GN = Mat1a PE = $1 \mathrm{SV}=2$

P18298

S-adenosylmethionine synthase

isoform type- $2 \mathrm{OS}=$ Rattus

P10860
Tubulin beta $-4 \mathrm{~B}$ chain OS $=$ Rattus

$\mathrm{OS}=$ Rattus norvegicus $\mathrm{GN}=$ Pdi

ATP synthase subunit beta

$\mathrm{S}=$ Rattus norvegicus $\mathrm{GN}=\mathrm{Pdia}$

Selenium-binding protein 1

$\mathrm{OS}=$ Rattus norvegicus

$\mathrm{GN}=$ Selenbp $1 \mathrm{PE}=1 \mathrm{SV}=1$

norvegicus GN $=\mathrm{Eno} 1 \mathrm{PE}=1 \mathrm{SV}=4$

$\mathrm{S}$-adenosylmethionine synthase

isoform type- 1 OS = Rattus

norvegicus GN $=$ Mat2a $P E=1 \mathrm{SV}=1$

\section{3}

188

Glutamate dehydrogenase 1.

mitochondrial OS $=$ Rattus

norvegicus $\mathrm{GN}=\mathrm{Glud} 1 \mathrm{PE}=1 \mathrm{SV}=2$
4701

5832

5409

175

2776

10854

1690

5530

2236

2236

2108

417

305

4457

1377

49,671

56,623

60,806

60,806

56,815

46,301

5

48,173

52,532

47,128

47,014

47,141

53,653

55,110

$\left(\frac{10}{20}\right.$

$$
43,698
$$

31

3974

43,716

8.05

61,416 microtubule-based process

Other

Other

microtubule-based process

Cell redox homeostasis

sulfur metabolism

energy metabolism; sulfur metabolism

beta-alanine metabolic

process, thymine catabolic

process, uracil metabolic

and catabolic process

cell redox homeostasis

ATP synthesis, Hydrogen

ion transport, Io

ion transport, lon

cell redox homeostasis

protein transporter

gglycolysis/gluconeogenesis

gglycolysis/gluconeogenesis

gglycolysis/gluconeogenesis

amine and polyamine

biosynthesis; carnitine biosynthesis

amino-acid degradation,

biosynthetic process,

L-alanine catabolic process

amino-acid biosynthesis;

S-adenosyl-L-methionine

biosynthesis;

S-adenosyl-L-methionine

from L-methionine

amino-acid biosynthesis:

S-adenosyl-L-methionine

biosynthesis

oxidoreductase, allosteric

regulation

Other

Other
Oxidative stress

Energy metabolism

Energy metabolism

Oxidative stress

Energy metabolism

Chaperone

Transport

Carbohydrate

metabolism

Carbohydrate

metabolism

Carbohydrate

metabolism

Amino-acid

metabolism

Amino-acid

metabolism

Amino-acid

metabolism
$\mathrm{C}=\mathrm{Zn}$; DM1 $=\mathrm{Se}$ and

$\mathrm{Zn} ; \mathrm{DM} 1+\mathrm{I}=\mathrm{Cu}, \mathrm{Mg}$, Se

and $\mathrm{Zn}$

$\mathrm{C}=\mathrm{Zn} ; \mathrm{DM} 1+\mathrm{I}=\mathrm{Se}$

$\mathrm{DM} 1=\mathrm{Mg}$ and Se;

$\mathrm{DM} 1+\mathrm{I}=\mathrm{Cu}$ and $\mathrm{Mg}$

DM1 = Se; DM1 + I = C

and Se

$\mathrm{C}=\mathrm{Zn} ; \mathrm{DM} 1=\mathrm{Se}$; $\mathrm{DM} 1+\mathrm{I}=\mathrm{Cu}, \mathrm{Mg}$ and $\mathrm{Se}$

$\mathrm{DM} 1=\mathrm{Cu}$ and Se;

$\mathrm{DM} 1+\mathrm{I}=\mathrm{Cu}, \mathrm{Mg}$, Se

and $\mathrm{Zn}$

$\mathrm{DM} 1=\mathrm{Se} ; \mathrm{DM} 1+\mathrm{I}=\mathrm{Cu}$

$\mathrm{Mg}$, Se and $\mathrm{Zn}$

DM1 = Se and Zn;

$\mathrm{DM} 1+\mathrm{I}=\mathrm{Cu}, \mathrm{Mg}$ and $\mathrm{Zn}$ 


\begin{tabular}{|c|c|c|c|c|c|c|c|c|c|c|}
\hline Spot ID & Protein entry & Protein & Score & $\begin{array}{l}\mathrm{pI}(\text { theo- } \\
\text { retical) }\end{array}$ & $\begin{array}{l}\mathrm{Mw}(\mathrm{Da}, \\
\text { theoretical })\end{array}$ & Peptides & Coverage (\%) & Biological process & $\begin{array}{l}\text { Metabolism } \\
\text { associated }\end{array}$ & $\begin{array}{l}\mathrm{Cu}, \mathrm{Mg} \text {, Se and } \mathrm{Zn} \\
\text { presence }\end{array}$ \\
\hline 73 & P85968 & $\begin{array}{l}\text { 6-phosphogluconate } \\
\text { dehydrogenase_decarboxylating } \\
\text { OS = Rattus norvegicus GN= Pgd } \\
\mathrm{PE}=1 \mathrm{SV}=1\end{array}$ & 110 & 6.57 & 53,236 & 36 & 3.52 & $\begin{array}{l}\text { Gluconate utilization, } \\
\text { Pentose shunt }\end{array}$ & $\begin{array}{l}\text { Carbohydrate } \\
\text { metabolism }\end{array}$ & $\begin{array}{l}\mathrm{DM} 1+\mathrm{I}=\mathrm{Cu}, \mathrm{Mg}, \mathrm{Se} \\
\text { and } \mathrm{Zn}\end{array}$ \\
\hline 75 & Q64640 & $\begin{array}{l}\text { Adenosine kinase } O S=\text { Rattus } \\
\text { norvegicus } G N=A d k P E=1 S V=3\end{array}$ & 2104 & 5.72 & 40,134 & 36 & 26.59 & purine salvage & Lipid metabolism & $\begin{array}{l}\mathrm{DM} 1=\mathrm{Se} ; \mathrm{DM} 1+\mathrm{I}=\mathrm{Cu} \text {, } \\
\text { Mg, Se and Zn }\end{array}$ \\
\hline \multirow[t]{3}{*}{77} & Q03248 & $\begin{array}{l}\text { Beta-ureidopropionase } \mathrm{OS}=\text { Rattus } \\
\text { norvegicus } \mathrm{GN}=\mathrm{Upb} 1 \mathrm{PE}=1 \mathrm{SV}=1\end{array}$ & 2812 & 6.74 & 44,042 & 33 & 25.45 & $\begin{array}{l}\text { amino-acid biosynthesis; } \\
\text { beta-alanine biosynthesis }\end{array}$ & $\begin{array}{l}\text { Amino-acid } \\
\text { metabolism }\end{array}$ & $\begin{array}{l}\mathrm{C}=\mathrm{Mg}, \mathrm{DM} 1=\mathrm{Se} \text { and } \\
\mathrm{DM} 1+\mathrm{I}=\mathrm{Cu}, \mathrm{Mg}, \mathrm{Se}\end{array}$ \\
\hline & P32755 & $\begin{array}{l}\text { 4-hydroxyphenylpyruvate } \\
\text { dioxygenase } \mathrm{OS}=\text { Rattus } \\
\text { norvegicus } \mathrm{GN}=\mathrm{Hpd} \mathrm{PE}=1 \mathrm{SV}=3\end{array}$ & 2625 & 6.29 & 45,112 & 29 & 15.04 & $\begin{array}{l}\text { L-phenylalanine catabolic } \\
\text { proces, tyrosine catabolic } \\
\text { process }\end{array}$ & $\begin{array}{l}\text { Amino-acid } \\
\text { metabolism }\end{array}$ & and $\mathrm{Zn}$ \\
\hline & P25093 & $\begin{array}{l}\text { Fumarylacetoacetase } \mathrm{OS}=\mathrm{Rattus} \\
\text { norvegicus } \mathrm{GN}=\mathrm{Fah} \mathrm{PE}=1 \mathrm{SV}=1\end{array}$ & 1804 & 6.67 & 45,976 & 31 & 20.47 & $\begin{array}{l}\text { Phenylalanine catabolism, } \\
\text { Tyrosine catabolism }\end{array}$ & $\begin{array}{l}\text { Amino-acid } \\
\text { metabolism }\end{array}$ & \\
\hline 78 & Q6P756 & $\begin{array}{l}\text { Adaptin ear-binding } \\
\text { coat-associated protein } 2 \\
\text { OS }=\text { Rattus norvegicus } \mathrm{GN}=\text { Necap2 } \\
\mathrm{PE}=1 \mathrm{SV}=2\end{array}$ & 139 & 7.72 & 28,405 & 18 & 10.27 & endocytosis & Transport & $\begin{array}{l}\mathrm{C}=\mathrm{Mg} \text { and } \mathrm{Zn} ; \\
\mathrm{DM} 1=\mathrm{Mg} \text { and } \mathrm{Se} ; \\
\mathrm{DM} 1+\mathrm{I}=\mathrm{Cu} \text { and } \mathrm{Mg}\end{array}$ \\
\hline \multirow[t]{2}{*}{79} & P07824 & $\begin{array}{l}\text { Arginase }-1 \mathrm{OS}=\text { Rattus norvegicus } \\
\mathrm{GN}=\operatorname{Arg} 1 \mathrm{PE}=1 \mathrm{SV}=2\end{array}$ & 8906 & 6.76 & 34,973 & 31 & 41.8 & Urea cycle & $\begin{array}{l}\text { Amino-acid } \\
\text { metabolism }\end{array}$ & $\begin{array}{l}\mathrm{C}=\mathrm{Zn} ; \mathrm{DM} 1=\mathrm{Se} ; \\
\mathrm{DM} 1+\mathrm{I}=\mathrm{Cu}, \mathrm{Mg} \text { and } \mathrm{Zn}\end{array}$ \\
\hline & P27867 & $\begin{array}{l}\text { Sorbitol dehydrogenase } \mathrm{OS}=\text { Rattus } \\
\text { norvegicus } \mathrm{GN}=\text { Sord } \mathrm{PE}=2 \mathrm{SV}=4\end{array}$ & 176 & 7.14 & 38,235 & 30 & 7.84 & Fructose biosynthesis & $\begin{array}{l}\text { Carbohydrate } \\
\text { metabolism }\end{array}$ & \\
\hline 86 & P46844 & $\begin{array}{l}\text { Biliverdin reductase } \mathrm{AOS}=\text { Rattus } \\
\text { norvegicus } \mathrm{GN}=\mathrm{Blvra} \mathrm{PE}=1 \mathrm{SV}=1\end{array}$ & 807 & 5.82 & 33,566 & 28 & 13.9 & $\begin{array}{l}\text { biliverdin reductase } \\
\text { activity }\end{array}$ & Other & $\begin{array}{l}\mathrm{C}=\mathrm{Cu} ; \mathrm{DM} 1=\mathrm{Se} \\
\mathrm{DM} 1+\mathrm{I}=\mathrm{Mg}\end{array}$ \\
\hline 87 & D3ZHP7 & $\begin{array}{l}\text { Serine/threonine-protein kinase } \\
\text { ULK3 OS }=\text { Rattus norvegicus } \\
\text { GN }=\text { Ulk3 PE }=3 \text { SV }=1\end{array}$ & 181 & 6.34 & 53,419 & 20 & 51.85 & Autophagy & Nucleotide & $\begin{array}{l}\mathrm{C}=\mathrm{Cu} ; \mathrm{DM} 1+\mathrm{I}=\mathrm{Mg}, \mathrm{Se} \\
\text { and } \mathrm{Zn}\end{array}$ \\
\hline \multirow[t]{2}{*}{88} & Q5I0J9 & $\begin{array}{l}\text { Putative } L \text {-aspartate } \\
\text { dehydrogenase } O S=\text { Rattus } \\
\text { norvegicus } G N=A s p d h P E=2 S V=1\end{array}$ & 5716 & 5.52 & 31,260 & 23 & 29.21 & $\begin{array}{l}\text { aspartate dehydrogenase } \\
\text { activity }\end{array}$ & Other & $\begin{array}{l}\mathrm{C}=\mathrm{Cu} ; \mathrm{DM} 1=\mathrm{Se} \\
\mathrm{DM} 1+\mathrm{I}=\mathrm{Mg} \text { and } \mathrm{Zn}\end{array}$ \\
\hline & P17988 & $\begin{array}{l}\text { Sulfotransferase } 1 \mathrm{~A} 1 \mathrm{OS}=\text { Rattus } \\
\text { norvegicus } \mathrm{GN}=\text { Sult } 1 \mathrm{a} 1 \mathrm{PE}=1 \\
\mathrm{SV}=1\end{array}$ & 2500 & 6.37 & 33,906 & 20 & 26.62 & Transferase & Lipid metabolism & \\
\hline 91 & P13255 & $\begin{array}{l}\text { Glycine N-methyltransferase } \\
\mathrm{OS}=\mathrm{Rattus} \text { norvegicus } \mathrm{GN}=\mathrm{Gnmt} \\
\mathrm{PE}=1 \mathrm{SV}=2\end{array}$ & 12867 & 7.1 & 32,549 & 20 & 24.57 & $\begin{array}{l}\text { methyltransferase, } \\
\text { transferase }\end{array}$ & Other & $\begin{array}{l}\mathrm{DM} 1=\mathrm{Se} ; \mathrm{DM} 1+\mathrm{I}=\mathrm{Cu} \text {, } \\
\text { Mg and } \mathrm{Zn}\end{array}$ \\
\hline 92 & P00481 & $\begin{array}{l}\text { Ornithine carbamoyltransferase } \\
\text { mitochondrial } \mathrm{OS}=\mathrm{Rattus} \\
\text { norvegicus } \mathrm{GN}=\mathrm{Otc} \mathrm{PE}=1 \mathrm{SV}=1\end{array}$ & 2516 & 9.12 & 39,886 & 27 & 44.63 & Urea cycle & $\begin{array}{l}\text { Amino-acid } \\
\text { metabolism }\end{array}$ & $\begin{array}{l}\mathrm{C}=\mathrm{Cu}, \mathrm{DM} 1+\mathrm{I}=\mathrm{Cu}, \mathrm{Mg} \text {, } \\
\text { Se and } \mathrm{Zn}\end{array}$ \\
\hline \multirow[t]{4}{*}{94} & P04797 & $\begin{array}{l}\text { Glyceraldehyde-3-phosphate } \\
\text { dehydrogenase OS = Rattus } \\
\text { norvegicus } G N=\text { Gapdh } P E=1 S V=3\end{array}$ & 3136 & 8.14 & 35,828 & 29 & 19.88 & glycolysis/gluconeogenesis & $\begin{array}{l}\text { Carbohydrate } \\
\text { metabolism }\end{array}$ & $\begin{array}{l}\mathrm{C}=\mathrm{Cu} ; \mathrm{DM} 1=\mathrm{Se} \\
\mathrm{DM} 1+\mathrm{I}=\mathrm{Mg}, \mathrm{Se} \text { and } \mathrm{Zn}\end{array}$ \\
\hline & P04642 & $\begin{array}{l}\text { L-lactate dehydrogenase } A \text { chain } \\
\mathrm{OS}=\text { Rattus norvegicus } \mathrm{GN}=\text { Ldha } \\
\mathrm{PE}=1 \mathrm{SV}=1\end{array}$ & 812 & 8.45 & 36,451 & 24 & 2.71 & lactate & $\begin{array}{l}\text { Carbohydrate } \\
\text { metabolism }\end{array}$ & \\
\hline & P19629 & $\begin{array}{l}\text { L-lactate dehydrogenase } C \text { chain } \\
O S=\text { Rattus norvegicus } G N=L d h c \\
P E=1 S V=3\end{array}$ & 180 & 7.56 & 35,687 & 30 & 24.26 & lactate & $\begin{array}{l}\text { Carbohydrate } \\
\text { metabolism }\end{array}$ & \\
\hline & P04636 & $\begin{array}{l}\text { Malate dehydrogenase } \\
\text { mitochondrial } \mathrm{OS}=\text { Rattus } \\
\text { norvegicus } \mathrm{GN}=\mathrm{Mdh} 2 \mathrm{PE}=1 \mathrm{SV}=2\end{array}$ & 170 & 8.93 & 35,684 & 19 & 4.26 & tricarboxylic acid cycle & $\begin{array}{l}\text { Carbohydrate } \\
\text { metabolism }\end{array}$ & \\
\hline \multirow[t]{2}{*}{95} & P00884 & $\begin{array}{l}\text { Fructose-bisphosphate aldolase } B \\
O S=R a t t u s \text { norvegicus } G N=\text { Aldob } \\
P E=1 S V=2\end{array}$ & 4190 & 8.66 & 39,618 & 19 & 25.34 & Glycolysis & $\begin{array}{l}\text { Carbohydrate } \\
\text { metabolism }\end{array}$ & $\begin{array}{l}\mathrm{C}=\mathrm{Cu} ; \mathrm{DM} 1=\mathrm{Se} \\
\mathrm{DM} 1+\mathrm{I}=\mathrm{Mg}, \text { Se and } \mathrm{Zn}\end{array}$ \\
\hline & P00507 & $\begin{array}{l}\text { Aspartate aminotransferase } \\
\text { mitochondrial } \mathrm{OS}=\text { Rattus } \\
\text { norvegicus } \mathrm{GN}=\mathrm{Got} 2 \mathrm{PE}=1 \mathrm{SV}=2\end{array}$ & 1130 & 6.73 & 46,429 & 21 & 9.01 & Amino-acid biosynthesis & $\begin{array}{l}\text { Amino-acid } \\
\text { metabolism }\end{array}$ & \\
\hline
\end{tabular}


Glutathione $S$-transferase $\mathrm{Mu} 2$ $\mathrm{OS}=$ Rattus norvegicus $\mathrm{GN}=\mathrm{Gstm}$ $\mathrm{PE}=1 \mathrm{SV}=2$ Glutathione S-transferase $\mathrm{Yb}-3$ $\mathrm{OS}=$ Rattus norvegicus $\mathrm{GN}=\mathrm{Gstm} 3$ $\mathrm{PE}=1 \mathrm{SV}=2$

Glutathione S-transferase Mu 1 $\mathrm{OS}=$ Rattus norvegicus $\mathrm{GN}=\mathrm{Gstm} 1$ $\mathrm{OS}=$ Rattus norv
$\mathrm{PE}=1 \mathrm{SV}=2$ Carbonic anhydrase $1 \mathrm{OS}=$ Rattus norvegicus $\mathrm{GN}=\mathrm{Ca} 1 \mathrm{PE}=1 \mathrm{SV}=1$ Omega-amidase NIT2 OS = Rattus norvegicus $\mathrm{GN}=\mathrm{Nit} 2 \mathrm{PE}=1 \mathrm{SV}=1$ Redox-regulatory protein FAM213A OS = Rattus norvegicu $\mathrm{GN}=\mathrm{Fam} 213 \mathrm{aE}=1 \mathrm{SV}=1$

Electron transfer flavoprotein subunit alpha mitochondrial

$\mathrm{OS}=$ Rattus norvegicus $\mathrm{GN}=\mathrm{Etfa}$ $\mathrm{PE}=1 \mathrm{SV}=4$

108

P52847 Sulfotransferase family cytosolic $1 \mathrm{~B}$ member 1 OS = Rattus norvegicus $\mathrm{GN}=$ = Sult1b1 $\mathrm{PE}=1$ norvegicus $\mathrm{GN}=$ Sult $1 \mathrm{~b} 1 \mathrm{PE}=1$ SV $=2$

P19112

Fructose-1_6-bisphosphatase 1 $\mathrm{OS}=$ Rattus norvegicus $\mathrm{GN}=\mathrm{Fbp} 1$ $\mathrm{PE}=1 \mathrm{SV}=2$

Q9Z1N1 Fructose-1_6-bisphosphatase isozyme $2 \mathrm{OS}=$ Rattus norvegicus $\mathrm{GN}=\mathrm{Fbp} 2 \mathrm{PE}=2 \mathrm{SV}=1$

035244 Peroxiredoxin -6 OS = Rattus norvegicus $\mathrm{GN}=\operatorname{Prdx} 6 \mathrm{PE}=1 \mathrm{SV}=3$ Proteasome subunit beta type- 4 $\mathrm{OS}=$ Rattus norvegicus $\mathrm{GN}=\mathrm{Psmb} 4$ $\mathrm{PE}=1 \mathrm{SV}=2$

Thioredoxin-dependent peroxide reductase_mitochondrial

$\mathrm{OS}=$ Rattus norvegicus GN = Prdx 3 $\mathrm{PE}=1 \mathrm{SV}=2$

Glutathione peroxidase 1

$\mathrm{OS}=$ Rattus norvegicus $\mathrm{GN}=\mathrm{Gpx} 1$ $\mathrm{PE}=1 \mathrm{SV}=4$

\begin{tabular}{|c|c|c|c|c|c|c|c|}
\hline 1111 & 8.89 & 25,559 & 20 & 21.62 & $\begin{array}{l}\text { glutathione transferase } \\
\text { activity }\end{array}$ & Oxidative stress & \\
\hline 1111 & 8.87 & 25,607 & 21 & 10.11 & $\begin{array}{l}\text { glutathione transferase } \\
\text { activity }\end{array}$ & Oxidative stress & \\
\hline 8573 & 6.91 & 25,703 & 21 & 16.51 & $\begin{array}{l}\text { glutathione transferase } \\
\text { activity }\end{array}$ & Oxidative stress & $\begin{array}{l}\mathrm{C}=\mathrm{Cu} ; \mathrm{DM} 1=\mathrm{Se} \\
\mathrm{DM} 1+\mathrm{I}=\mathrm{Cu}, \mathrm{Mg} \text { and } \mathrm{Zn}\end{array}$ \\
\hline 2575 & 6.84 & 25,681 & 22 & 30.28 & $\begin{array}{l}\text { glutathione transferase } \\
\text { activity }\end{array}$ & Oxidative stress & \\
\hline 1602 & 8.27 & 25,914 & 15 & 7.11 & $\begin{array}{l}\text { glutathione transferase } \\
\text { activity }\end{array}$ & Oxidative stress & \\
\hline 1436 & 6.89 & 29,431 & 23 & 9.23 & $\begin{array}{l}\text { Response to oxidative } \\
\text { stress }\end{array}$ & Oxidative stress & $\mathrm{C}=\mathrm{Cu}$ \\
\hline 322 & 6.86 & 28,300 & 18 & 8.81 & $\begin{array}{l}\text { Response to oxidative } \\
\text { stress }\end{array}$ & Oxidative stress & \\
\hline 4320 & 6.9 & 30,701 & 21 & 16.55 & omega-amidase activity & Other & $\begin{array}{l}\mathrm{C}=\mathrm{Cu}, \mathrm{Mg} \text { and } \mathrm{Se} ; \\
\mathrm{DM} 1=\mathrm{Se} ; \mathrm{DM} 1+\mathrm{I}=\mathrm{Mg}\end{array}$ \\
\hline 117 & 9.19 & 25,763 & 24 & 31.83 & Antioxidant & Oxidative stress & and Zn \\
\hline 1862 & 8.62 & 34,951 & 12 & 6.94 & electron transport & Energy metabolism & $\begin{array}{l}\mathrm{C}=\mathrm{Cu} \text { and } \mathrm{Se} ; \\
\mathrm{DM} 1+\mathrm{I}=\mathrm{Cu}, \mathrm{Mg} \text { and } \mathrm{Zn}\end{array}$ \\
\hline 935 & 8.16 & 34,835 & 23 & 8.46 & $\begin{array}{l}\text { lipid metabolism, steroid } \\
\text { metabolism }\end{array}$ & Lipid metabolism & $\begin{array}{l}\mathrm{C}=\mathrm{Cu}, \mathrm{Mg} \text { and } \mathrm{Se} ; \\
\mathrm{DM} 1=\mathrm{Se} ; \mathrm{DM} 1+\mathrm{I}=\mathrm{Cu} \text {, } \\
\mathrm{Mg} \text { and } \mathrm{Zn}\end{array}$ \\
\hline 5045 & 5.54 & 39,609 & 33 & 34.16 & gluconeogenesis & $\begin{array}{l}\text { Carbohydrate } \\
\text { metabolism }\end{array}$ & $\begin{array}{l}\mathrm{C}=\mathrm{Cu} ; \mathrm{DM} 1=\mathrm{Se} ; \\
\mathrm{DM} 1+\mathrm{I}=\mathrm{Cu}, \mathrm{Mg} \text { and } \mathrm{Zn}\end{array}$ \\
\hline 424 & 6.76 & 36,887 & 26 & 5.31 & gluconeogenesis & $\begin{array}{l}\text { Carbohydrate } \\
\text { metabolism }\end{array}$ & \\
\hline 8422 & 7.14 & 76,395 & 17 & 6.84 & redox regulation & Oxidative stress & $\begin{array}{l}\mathrm{C}=\mathrm{Cu} \text { and } \mathrm{Zn} ; \\
\mathrm{DM} 1=\mathrm{Se} ; \mathrm{DM} 1+\mathrm{I}=\mathrm{Cu},\end{array}$ \\
\hline 117 & 6.44 & 29,197 & 20 & 9.73 & $\begin{array}{l}\text { Hydrolase, Protease, } \\
\text { Threonine protease }\end{array}$ & Other & Mg, Se and Zn \\
\hline 107 & 7.14 & 28,295 & 18 & 18.59 & $\begin{array}{l}\text { negative regulation of } \\
\text { neuron apoptotic process }\end{array}$ & Oxidative stress & \\
\hline 2858 & 7.7 & 22,305 & 15 & 38.81 & $\begin{array}{l}\text { Oxidoreductase, } \\
\text { Peroxidase }\end{array}$ & Oxidative stress & $\begin{array}{l}\mathrm{C}=\mathrm{Cu} ; \mathrm{DM} 1=\mathrm{Cu} \text { and } \\
\text { Se; DM1 }+\mathrm{I}=\mathrm{Mg} \text { and } \mathrm{Zn}\end{array}$ \\
\hline 2729 & 8.27 & 22,109 & 19 & 33.33 & redox regulation & Oxidative stress & $\mathrm{C}=\mathrm{Cu}$ \\
\hline 2650 & 6.96 & 22,912 & 17 & 6.31 & $\begin{array}{l}\text { Hydrolase, Protease, } \\
\text { Threonine protease }\end{array}$ & Other & \\
\hline
\end{tabular}


Table 2 (Continued)

\begin{tabular}{|c|c|c|c|c|c|c|c|c|c|c|}
\hline Spot ID & Protein entry & Protein & Score & $\begin{array}{l}\text { pI (theo- } \\
\text { retical) }\end{array}$ & $\begin{array}{l}\mathrm{Mw}(\mathrm{Da}, \\
\text { theoretical) }\end{array}$ & Peptides & Coverage (\%) & Biological process & $\begin{array}{l}\text { Metabolism } \\
\text { associated }\end{array}$ & $\begin{array}{l}\mathrm{Cu}, \mathrm{Mg} \text {, Se and } \mathrm{Zn} \\
\text { presence }\end{array}$ \\
\hline 127 & P07895 & $\begin{array}{l}\text { Superoxide dismutase }[\mathrm{Mn}]_{-} \\
\text {mitochondrial OS }=\text { Rattus } \\
\text { norvegicus } \mathrm{GN}=\operatorname{Sod} 2 \mathrm{PE}=1 \mathrm{SV}=2\end{array}$ & 3761 & 8.96 & 24,674 & 18 & 13.07 & $\begin{array}{l}\text { response to oxidative } \\
\text { stress }\end{array}$ & Oxidative stress & $\begin{array}{l}\mathrm{C}=\mathrm{Cu} ; \mathrm{DM} 1=\mathrm{Mg} \text { and } \\
\mathrm{Se}\end{array}$ \\
\hline 128 & Q63716 & $\begin{array}{l}\text { Peroxiredoxin }-1 \mathrm{OS}=\text { Rattus } \\
\text { norvegicus } \mathrm{GN}=\operatorname{Prdx} 1 \mathrm{PE}=1 \mathrm{SV}=1\end{array}$ & 2872 & 8.27 & 22,109 & 19 & 31.56 & redox regulation & Oxidative stress & $\mathrm{C}=\mathrm{Cu}$ \\
\hline \multirow[t]{9}{*}{129} & P30713 & $\begin{array}{l}\text { Glutathione } S \text {-transferase theta- } 2 \\
\mathrm{OS}=\text { Rattus norvegicus } \mathrm{GN}=\mathrm{Gstt} 2 \\
\mathrm{PE}=1 \mathrm{SV}=3\end{array}$ & 4035 & 7.75 & 27,439 & 22 & 33.03 & $\begin{array}{l}\text { glutathione metabolic } \\
\text { process }\end{array}$ & Oxidative stress & $\mathrm{C}=\mathrm{Cu}$ and $\mathrm{Se}$ \\
\hline & P04905 & $\begin{array}{l}\text { Glutathione } \mathrm{S} \text {-transferase Mu } 1 \\
\mathrm{OS}=\text { Rattus norvegicus } \mathrm{GN}=\mathrm{Gstm} 1 \\
\mathrm{PE}=1 \mathrm{SV}=2\end{array}$ & 3785 & 8.27 & 25,914 & 18 & 18.59 & $\begin{array}{l}\text { olfaction, Sensory } \\
\text { transduction }\end{array}$ & Other & \\
\hline & P08010 & $\begin{array}{l}\text { Glutathione } \mathrm{S} \text {-transferase } \mathrm{Mu} 2 \\
\mathrm{OS}=\mathrm{Rattus} \text { norvegicus } \mathrm{GN}=\mathrm{Gstm} 2 \\
\mathrm{PE}=1 \mathrm{SV}=2\end{array}$ & 119 & 6.91 & 25,703 & 19 & 16.29 & $\begin{array}{l}\text { olfaction, Sensory } \\
\text { transduction }\end{array}$ & Other & \\
\hline & P04904 & $\begin{array}{l}\text { Glutathione } S \text {-transferase alpha- } 3 \\
\mathrm{OS}=\mathrm{Rattus} \text { norvegicus } \mathrm{GN}=\mathrm{Gsta} 3 \\
\mathrm{PE}=1 \mathrm{SV}=3\end{array}$ & 110 & 8.78 & 25,319 & 20 & 13.96 & Transferase & Oxidative stress & \\
\hline & Q6AXY0 & $\begin{array}{l}\text { Glutathione } \mathrm{S} \text {-transferase } \mathrm{A6} \\
\mathrm{OS}=\mathrm{Rattus} \text { norvegicus } \mathrm{GN}=\mathrm{Gsta} 6 \\
\mathrm{PE}=1 \mathrm{SV}=1\end{array}$ & 87 & 5.9 & 25,808 & 19 & 3.62 & $\begin{array}{l}\text { glutathione metabolic } \\
\text { process }\end{array}$ & Oxidative stress & \\
\hline & P46418 & $\begin{array}{l}\text { Glutathione } S \text {-transferase alpha- } 5 \\
\mathrm{OS}=\mathrm{Rattus} \text { norvegicus } \mathrm{GN}=\mathrm{Gsta5} \\
\mathrm{PE}=1 \mathrm{SV}=2\end{array}$ & 79 & 8.42 & 25,347 & 20 & 3.6 & $\begin{array}{l}\text { xenobiotic catabolic } \\
\text { process, response to drug, } \\
\text { response to nutrient levels }\end{array}$ & Oxidative stress & \\
\hline & P14942 & $\begin{array}{l}\text { Glutathione } S \text {-transferase alpha- } 4 \\
\mathrm{OS}=\mathrm{Rattus} \text { norvegicus } \mathrm{GN}=\mathrm{Gsta} 4 \\
\mathrm{PE}=1 \mathrm{SV}=2\end{array}$ & 79 & 6.77 & 25,510 & 21 & 3.6 & $\begin{array}{l}\text { glutathione metabolic } \\
\text { process }\end{array}$ & Oxidative stress & \\
\hline & P04903 & $\begin{array}{l}\text { Glutathione } S \text {-transferase alpha- } 2 \\
\mathrm{OS}=\mathrm{Rattus} \text { norvegicus } \mathrm{GN}=\mathrm{Gsta} 2 \\
\mathrm{PE}=2 \mathrm{SV}=2\end{array}$ & 79 & 8.89 & 25,559 & 20 & 3.6 & $\begin{array}{l}\text { glutathione metabolic } \\
\text { process }\end{array}$ & Oxidative stress & \\
\hline & P00502 & $\begin{array}{l}\text { Glutathione } S \text {-transferase alpha- } 1 \\
\mathrm{OS}=\mathrm{Rattus} \text { norvegicus } \mathrm{GN}=\mathrm{Gsta} 1 \\
\mathrm{PE}=1 \mathrm{SV}=3\end{array}$ & 79 & 8.87 & 25,607 & 46 & 31.46 & $\begin{array}{l}\text { glutathione metabolic } \\
\text { process }\end{array}$ & Oxidative stress & \\
\hline 132 & P15999 & $\begin{array}{l}\text { ATP synthase subunit alpha } \\
\text { mitochondrial OS= Rattus } \\
\text { norvegicus GN = Atp5a1 } \mathrm{PE}=1 \\
\mathrm{SV}=2\end{array}$ & 1435 & 9.22 & 59,754 & 22 & 7.34 & $\begin{array}{l}\text { ATP synthesis, Hydrogen } \\
\text { ion transport, Ion } \\
\text { transport, Transport }\end{array}$ & Energy metabolism & $\begin{array}{l}\mathrm{C}=\mathrm{Cu} ; \mathrm{DM} 1+\mathrm{I}=\mathrm{Cu} \\
\mathrm{Mg}, \mathrm{Se} \text { and } \mathrm{Zn}\end{array}$ \\
\hline \multirow[t]{3}{*}{133} & P52844 & $\begin{array}{l}\text { Estrogen sulfotransferase_isoform } \\
1 \mathrm{OS}=\text { Rattus norvegicus } \\
\mathrm{GN}=\text { Sult1e1 } \mathrm{PE}=2 \mathrm{SV}=1\end{array}$ & 1811 & 5.78 & 35,509 & 29 & 21.36 & Transferase & Other & $\begin{array}{l}\mathrm{C}=\mathrm{Cu} ; \mathrm{DM} 1+\mathrm{I}=\mathrm{Cu}, \mathrm{Mg} \\
\text { and } \mathrm{Zn}\end{array}$ \\
\hline & P49889 & $\begin{array}{l}\text { Estrogen sulfotransferase } \_ \text {isoform } \\
3 \mathrm{OS}=\mathrm{Rattus}_{\text {narvegicus }} \mathrm{GN}=\mathrm{Ste} \\
\mathrm{PE}=1 \mathrm{SV}=1\end{array}$ & 1500 & 5.57 & 35,416 & 29 & 16.61 & Transferase & Other & \\
\hline & P52845 & $\begin{array}{l}\text { Estrogen sulfotransferase } \_ \text {isoform } \\
2 O S=R_{\text {Rattus norvegicus }} \mathrm{GN}=\mathrm{Ste} 2 \\
\mathrm{PE}=2 \mathrm{SV}=1\end{array}$ & 1500 & 5.57 & 35,365 & 28 & 16.61 & Transferase & Other & \\
\hline 140 & P08010 & $\begin{array}{l}\text { Glutathione } S \text {-transferase } \mathrm{Mu} 2 \\
\mathrm{OS}=\mathrm{Rattus} \text { norvegicus } \mathrm{GN}=\mathrm{Gstm} 2 \\
\mathrm{PE}=1 \mathrm{SV}=2\end{array}$ & 550 & 6.91 & 25,703 & 30 & 25 & $\begin{array}{l}\text { olfaction, Sensory } \\
\text { transduction }\end{array}$ & Other & $\begin{array}{l}\mathrm{C}=\mathrm{Cu}, \mathrm{Mg} \text { and } \mathrm{Zn} ; \\
\mathrm{DM} 1=\mathrm{Se}\end{array}$ \\
\hline 142 & P09634 & $\begin{array}{l}\text { Homeobox protein Hox-A7 } \\
\text { (Fragment) } \mathrm{OS}=\mathrm{Rattus} \text { norvegicus } \\
\mathrm{GN}=\text { Hoxa7 } \mathrm{PE}=3 \mathrm{SV}=1\end{array}$ & 62 & 4.86 & 12,552 & 9 & 25.71 & Developmental protein & Other & $\begin{array}{l}\mathrm{C}=\mathrm{Cu} \text { and } \mathrm{Zn} ; \\
\mathrm{DM} 1=\mathrm{Se} ; \mathrm{DM} 1+\mathrm{I}=\mathrm{Mg} \\
\text { and } \mathrm{Zn}\end{array}$ \\
\hline
\end{tabular}




\begin{tabular}{|c|c|c|c|c|c|c|c|c|c|c|}
\hline \multirow[t]{2}{*}{143} & 035077 & $\begin{array}{l}\text { Glycerol-3-phosphate } \\
\text { dehydrogenase }[\mathrm{NAD}(+)]_{-} \\
\text {cytoplasmic } \mathrm{OS}=\mathrm{Rattus} \text { norvegicus } \\
\mathrm{GN}=\mathrm{Gpd} 1 \mathrm{PE}=1 \mathrm{SV}=4\end{array}$ & 782 & 6.16 & 37,453 & 28 & 18.62 & glycolysis/gluconeogenesis & $\begin{array}{l}\text { Carbohydrate } \\
\text { metabolism }\end{array}$ & $\begin{array}{l}\mathrm{C}=\mathrm{Cu} \text { and } \mathrm{Zn} ; \\
\mathrm{DM} 1=\mathrm{Mg} \text { and } \mathrm{Se} \\
\mathrm{DM} 1+\mathrm{I}=\mathrm{Mg} \text { and } \mathrm{Zn}\end{array}$ \\
\hline & Q8CG45 & $\begin{array}{l}\text { Aflatoxin } \mathrm{B} 1 \text { aldehyde reductase } \\
\text { member } 2 \mathrm{OS}=\text { Rattus norvegicus } \\
\mathrm{GN}=\text { Akr7a2 } \mathrm{PE}=1 \mathrm{SV}=2\end{array}$ & 245 & 8.35 & 40,675 & 21 & 28.34 & Oxidoreductase & Other & \\
\hline 145 & P31210 & $\begin{array}{l}\text { 3-oxo-5-beta-steroid } \\
\text { 4-dehydrogenase } \mathrm{OS}=\text { Rattus } \\
\text { norvegicus GN = Akr1d1 } \mathrm{PE}=1 \\
\mathrm{SV}=1\end{array}$ & 2741 & 6.18 & 37,378 & 101 & 26.38 & bile acid catabolic process & Lipid metabolism & $\begin{array}{l}\mathrm{C}=\mathrm{Cu} ; \mathrm{DM} 1=\mathrm{Se} ; \\
\mathrm{DM} 1+\mathrm{I}=\mathrm{Mg} \text { and } \mathrm{Se}\end{array}$ \\
\hline 146 & P24329 & $\begin{array}{l}\text { Thiosulfate sulfurtransferase } \\
\mathrm{OS}=\text { Rattus norvegicus } \mathrm{GN}=\mathrm{Tst} \\
\mathrm{PE}=1 \mathrm{SV}=3\end{array}$ & 1131 & 7.77 & 33,407 & 20 & 10.44 & $\begin{array}{l}\text { epithelial cell } \\
\text { differentiation synthesis }\end{array}$ & Other & $\mathrm{C}=\mathrm{Cu}$ \\
\hline \multirow[t]{3}{*}{147} & Q63797 & $\begin{array}{l}\text { Proteasome activator complex } \\
\text { subunit } 1 \mathrm{OS}=\mathrm{Rattus} \text { norvegicus } \\
\mathrm{GN}=\text { Psme } 1 \mathrm{PE}=2 \mathrm{SV}=1\end{array}$ & 1544 & 5.77 & 28,577 & 25 & 20.08 & innate immune response & Other & $\begin{array}{l}\mathrm{C}=\mathrm{Cu} ; \mathrm{DM} 1=\mathrm{Se} \\
\mathrm{DM} 1+\mathrm{I}=\mathrm{Mg}, \mathrm{Se} \text { and } \mathrm{Zn}\end{array}$ \\
\hline & P13803 & $\begin{array}{l}\text { Electron transfer flavoprotein } \\
\text { subunit alpha_ } \text { mitochondrial } \\
\mathrm{OS}=\text { Rattus norvegicus } \mathrm{GN}=\mathrm{Etfa} \\
\mathrm{PE}=1 \mathrm{SV}=4\end{array}$ & 182 & 8.62 & 34,951 & 24 & 5.11 & electron transport & Energy metabolism & \\
\hline & P23680 & $\begin{array}{l}\text { Serum amyloid P-component } \\
O S=\text { Rattus norvegicus } G N=A p c s \\
P E=2 S V=2\end{array}$ & 106 & 5.5 & 26,176 & 17 & 5.26 & innate immune response & Other & \\
\hline \multirow[t]{2}{*}{148} & Q5XI73 & $\begin{array}{l}\text { Rho GDP-dissociation inhibitor } 1 \\
\text { OS }=\text { Rattus norvegicus } \\
\text { GN }=\text { Arhgdia } P E=1 \mathrm{SV}=1\end{array}$ & 3089 & 5.1 & 23,407 & 44 & 22.06 & $\begin{array}{l}\text { cellular response to redox } \\
\text { state }\end{array}$ & Oxidative stress & $\mathrm{C}=\mathrm{Cu} ; \mathrm{DM} 1+\mathrm{I}=\mathrm{Mg}$ \\
\hline & P46953 & $\begin{array}{l}\text { 3-hydroxyanthranilate } \\
\text { 3_4-dioxygenase } \mathrm{OS}=\mathrm{Rattus} \\
\text { norvegicus } \mathrm{GN}=\mathrm{Haao} \mathrm{PE}=1 \mathrm{SV}=2\end{array}$ & 2132 & 5.57 & 32,582 & 100 & 27.62 & $\begin{array}{l}\text { cofactor biosynthesis; } \\
\mathrm{NAD}(+) \text { biosynthesis }\end{array}$ & Other & \\
\hline 149 & Q63797 & $\begin{array}{l}\text { Proteasome activator complex } \\
\text { subunit } 1 \mathrm{OS}=\mathrm{Rattus} \text { norvegicus } \\
\mathrm{GN}=\mathrm{Psme} 1 \mathrm{PE}=2 \mathrm{SV}=1\end{array}$ & 733 & 5.77 & 28,577 & 25 & 21.69 & innate immune response & Other & $\begin{array}{l}\mathrm{C}=\mathrm{Cu}, \mathrm{Mg} \text { and } \mathrm{Zn} ; \\
\mathrm{DM} 1+\mathrm{I}=\mathrm{Mg}\end{array}$ \\
\hline 150 & P85973 & $\begin{array}{l}\text { Purine nucleoside phosphorylase } \\
\mathrm{OS}=\mathrm{Rattus} \text { norvegicus } \mathrm{GN}=\mathrm{Pnp} \\
\mathrm{PE}=1 \mathrm{SV}=1\end{array}$ & 5621 & 6.46 & 32,302 & 21 & 38.41 & immune response & Nucleotide & $\begin{array}{l}\mathrm{C}=\mathrm{Cu} ; \mathrm{DM} 1=\mathrm{Se} ; \\
\mathrm{DM} 1+\mathrm{I}=\mathrm{Mg}, \mathrm{Se} \text { and } \mathrm{Zn}\end{array}$ \\
\hline 156 & Q63716 & $\begin{array}{l}\text { Peroxiredoxin }-1 \mathrm{OS}=\text { Rattus } \\
\text { norvegicus } \mathrm{GN}=\operatorname{Prdx} 1 \mathrm{PE}=1 \mathrm{SV}=1\end{array}$ & 2026 & 8.27 & 22,109 & 18 & 21.11 & redox regulation & Oxidative stress & $\mathrm{DM} 1=\mathrm{Se}$ \\
\hline \multirow[t]{2}{*}{160} & Q68FU3 & $\begin{array}{l}\text { Electron transfer flavoprotein } \\
\text { subunit beta } \mathrm{OS}=\mathrm{Rattus} \\
\text { norvegicus } \mathrm{GN}=\mathrm{Etfb} \mathrm{PE}=2 \mathrm{SV}=3\end{array}$ & 7067 & 7.61 & 27,687 & 17 & 26.27 & $\begin{array}{l}\text { electron transport, } \\
\text { transport }\end{array}$ & Energy metabolism & DM1 $=$ Mg \\
\hline & P08010 & $\begin{array}{l}\text { Glutathione } S \text {-transferase } \mathrm{Mu} 2 \\
\mathrm{OS}=\mathrm{Rattus} \text { norvegicus } \mathrm{GN}=\mathrm{Gstm} 2 \\
\mathrm{PE}=1 \mathrm{SV}=2\end{array}$ & 2130 & 6.91 & 25,703 & 22 & 33.49 & $\begin{array}{l}\text { glutathione transferase } \\
\text { activity }\end{array}$ & Oxidative stress & \\
\hline \multirow[t]{2}{*}{161} & P04905 & $\begin{array}{l}\text { Glutathione } \mathrm{S} \text {-transferase } \mathrm{Mu} 1 \\
\mathrm{OS}=\mathrm{Rattus} \text { norvegicus } \mathrm{GN}=\mathrm{Gstm} 1 \\
\mathrm{PE}=1 \mathrm{SV}=2\end{array}$ & 10826 & 8.27 & 25,914 & 22 & 36.24 & $\begin{array}{l}\text { glutathione transferase } \\
\text { activity }\end{array}$ & Oxidative stress & $\begin{array}{l}\mathrm{C}=\mathrm{Cu} ; \mathrm{DM} 1+\mathrm{I}=\mathrm{Mg} \\
\text { and } \mathrm{Zn}\end{array}$ \\
\hline & P29411 & $\begin{array}{l}\text { GTP:AMP phosphotransferase AK3 } \\
\text { mitochondrial } \mathrm{OS}=\mathrm{RattuS} \\
\text { norvegicus } \mathrm{GN}=\mathrm{Ak} 3 \mathrm{PE}=2 \mathrm{SV}=2\end{array}$ & 278 & 8.89 & 25,438 & 20 & 14.98 & $\begin{array}{l}\text { homeostasis of cellular } \\
\text { nucleotides }\end{array}$ & Nucleotide & \\
\hline
\end{tabular}




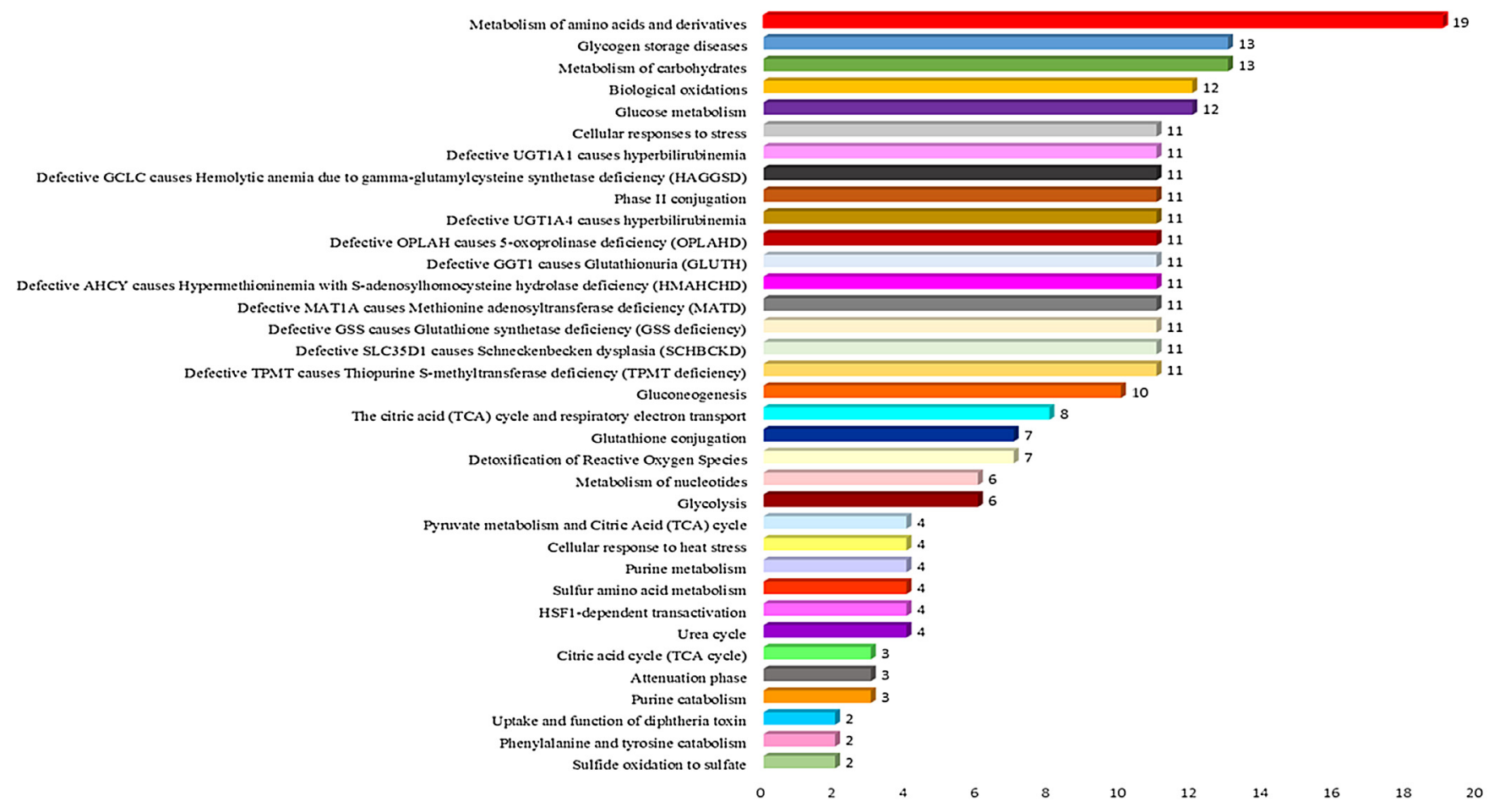

Fig. 2. Pathways with FDR $<0.05$ using the Reactome FI.

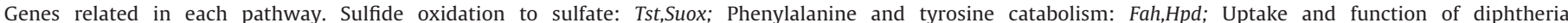

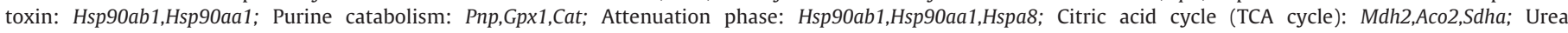

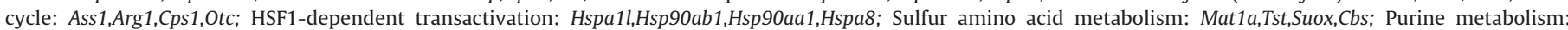

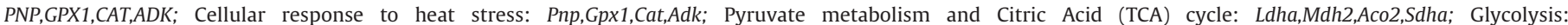

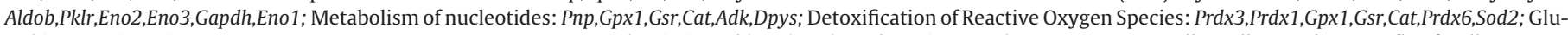

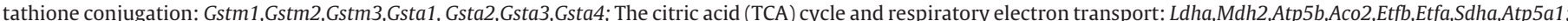

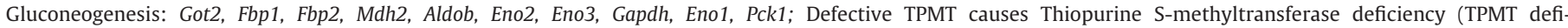

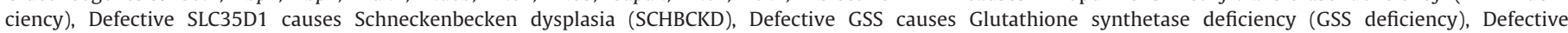

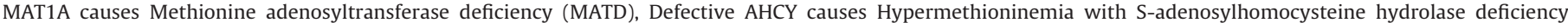

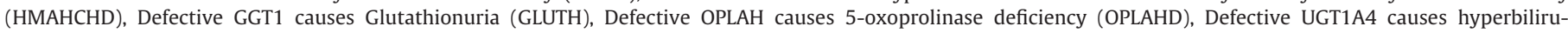

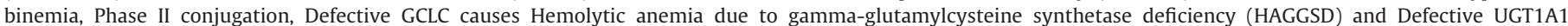

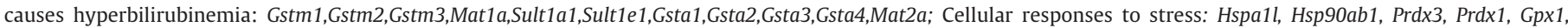

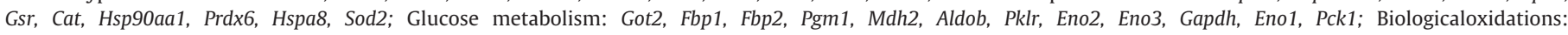

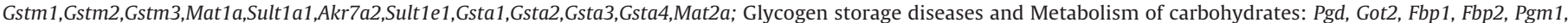

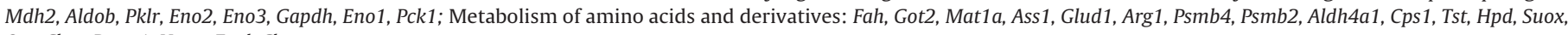
Otc, Ckm, Psme1, Haao, Ftcd, Cbs.

isoform type 1 and 2 (MAT1A and MAT2A) are reported in the literature as metal ion-binding proteins; this protein has Mg-finger metal-binding domains [34]. MAT1A and MAT2A catalyze the formation of S-adenosylmethionine from methionine and ATP [34]. Most significant was the protein bound in DM1 and DM1 + I with $\mathrm{Zn}$, as $\mathrm{Zn}$ and $\mathrm{Mg}$ have the same properties that can interfere with some modifications in these proteins. Propionyl-CoA carboxylase alpha chain (PCCA) was detected with $\mathrm{Cu}$ in $\mathrm{C}$. $\mathrm{Cu}$ is expected to bind by amino acids containing side chains with soft or borderline ligands such as histidine, cysteine and methionine [35], which could explain this presence because PCCA is composed of 737 amino acids where $2.4 \%$ are histidine, $1.5 \%$ cysteine and $2.8 \%$ methionine (UniProtKB/Swiss-Prot - www.uniprot.org).

\subsubsection{Chaperone and oxidative stress metabolism}

Heat shock proteins protect other proteins from stress, promote protein folding and prevent protein aggregation [36]. In spot 10, heat shock $70 \mathrm{kDa}$ protein 4 (HSPA4) showed the presence of $\mathrm{Cu}$ and Se in DM1 + I. In spot 33, stress-70 protein (HSPA9) and heat shock cognate $71 \mathrm{kDa}$ (HSPA8) showed the presence of $\mathrm{Cu}, \mathrm{Mg}$, Se and $\mathrm{Zn}$. In spot 41, $78 \mathrm{kDa}$ glucose-regulated protein (HSPA5), heat shock $70 \mathrm{kDa}$ protein 1-like and 1A/1 B (HSPA1L and HSPA1A), HSPA8 and heat shock-related $70 \mathrm{kDa}$ protein 2 (HSPA2) showed the presence of Se in DM1 and $\mathrm{Cu}$ and $\mathrm{Mg}$ in DM1+I. In spot 42, HSPA8, HSPA1A, HSPA2 and HSPA1L showed the presence of $\mathrm{Se}$ in DM1 and $\mathrm{Cu}, \mathrm{Mg}$ and Se in DM1 + I. The literature reported metal binding just in the small heat shock protein $\alpha$-crystallin that binds with $\mathrm{Cu}$ in the core domain, inducing increased dynamics at the dimer interface and modulating anti-aggregation [37]. The literature does not have any other report of metal binding or association with metals in heat shock proteins; our study could suggest some alterations to treatment with insulin in that the ions can bind with these proteins to protect them from oxidative stress generated in the diabetic condictions. Peroxiredoxins are responsible for the degradation of peroxides and thiol-dependent enzymes; peroxiredoxin-1 (PRX1) was found in three spots (124, 128 and 156) with the presence of Cu detected in C and Se in DM1. Another isoform of PRX (peroxiredoxin-6, PRX6) was found in two spots: spot 27 with $\mathrm{Cu}$ and $\mathrm{Mg}$ in DM1, and spot 120 with $\mathrm{Cu}$ and $\mathrm{Zn}$ in C, Se in DM1 and $\mathrm{Cu}, \mathrm{Mg}$, Se and $\mathrm{Zn}$ in DM1 + I. The literature does not report any binding or association of these enzymes with $\mathrm{Cu}, \mathrm{Mg}$, Se and $\mathrm{Zn}$; in DM1 the PRX-1 and 6 had a presence of Se that could change the function of these proteins in the degradation of peroxides. Different isoforms of glutathione S-transferase were found in this study. This enzyme plays a key role in enzymatic detoxification [38]. The results showed association with $\mathrm{Cu}$ in C, Se in DM1 and 
$\mathrm{Mg}$ and $\mathrm{Zn}$ in DM1 + I; can be associated with some modification of GST thiol groups that can interfere in their function. Carbonic anhydrase 1 and 3 (CA1 and CA3) are Zn metalloenzymes. In this study, these enzymes were found with the presence of $\mathrm{Cu}$ in $\mathrm{C}$. As $\mathrm{Zn}$ has many characteristics similar to $\mathrm{Cu}, \mathrm{Cu}$ can bind to the CA1 and CA3 domains.

\subsubsection{Carbohydrate and energy metabolism}

Phosphoglucomutase-1 (PGM1) plays a key role in carbohydrate metabolism by reversibly catalyzing the interconversion of glucose-1-phosphate to glucose-6-phosphate by the transfer of a phosphate between the C6 and C1 hydroxyl groups of glucose [39]. PGM1 is a ubiquitous metalloenzyme that binds one $\mathrm{Mg}^{2+}$ ion per subunit. In this study, $\mathrm{Cu}, \mathrm{Mg}$ and Se presence was found in PGM1. The presence of cysteine (weak base) in the peptide sequence may promote the association of $\mathrm{Cu}$ and Se in this enzyme. Alpha, beta and gamma enolase (ENO1, ENO3 and ENO2) that are involved in gluconeogenesis and glycolysis were found in spot 67 [40]. ENO1 is a $\mathrm{Mg}$ metalloenzyme that binds two $\mathrm{Mg}^{2+}$ per subunit, and ENO2 and 3 require $\mathrm{Mg}^{2+}$ for catalysis and for stabilizing the dimer [41]. In our study, the presence of $\mathrm{Cu}$ and Se was found in DM1 and $\mathrm{Cu}, \mathrm{Mg}$, Se and $\mathrm{Zn}$ in DM1 + I. Thus, it may imply some alteration in this enzyme in DM1 and DM1 + I that can interfere in carbohydrate metabolism and glycemia control. Spot 113 showed two Mg metalloenzymes: fructose 1,6-bisphosphatase 1 (FBP1) and fructose 1,6-bisphosphatase isozyme 2 (FBP2) which bind three $\mathrm{Mg}^{2+}$ ions per subunit and are involved in the production of fructose 1,6bisphosphate [42]. They showed the presence of Cu in C, Se in DM1 and $\mathrm{Cu}, \mathrm{Mg}$ and $\mathrm{Se}$ in $\mathrm{DM} 1+\mathrm{I}$. The cysteine present in the peptide sequence may promote the association of $\mathrm{Cu}$ and Se observed in this enzyme. In spot 34, glyceraldehyde-3-phosphate dehydrogenase (GAPDH), L-lactate dehydrogenase $A$ and $C$ chain (LDHA and LDHC) and malate dehydrogenase (MDH2) were found with the presence of Se in DM1 and Se and Zn in DM1 + I. The literature does not report any metal-binding association with these enzymes. Since these enzymes have cysteine in their sequences, we can infer this association in groups DM1 and DM1 $+\mathrm{I}$.

\section{Conclusion}

The determination of copper, magnesium, selenium and zinc bound to different proteins related to different metabolic processes can provide important information about the activity and function of the entire proteome. The literature has poor information about these associations, particularly related to diabetes and insulin treatment. However, the results shown in this manuscript could represent a mechanism for understanding the interactions and changes in DM1 pathology.

\section{References}

[1] P. Manna, J. Das, J. Ghosh, P.C. Sil, Contribution of type 1 diabetes to rat liver dysfunction and cellular damage via activation of NOS, PARP IkappaBalpha/NF-kappaB, MAPKs, and mitochondria-dependent pathways: prophylactic role of arjunolic acid, Free Radic. Biol. Med. 48 (2010) 1465-1484

[2] I.T.L. Bresolin, E.A. Miranda, S.M.A. Bueno, Cromatografia de afinidade poríons Metálicos Imobilizados (IMAC) de biomoléculas: aspectos fundamentais e aplicações tecnológicas, Quim. Nova. 32 (2009) 1288-1296.

[3] J.S. Garcia, C.S. De Magalhães, M.A.Z. Arruda, Trends in metal-binding and metalloprotein analysis, Talanta 69 (2006) 1-15.

[4] M. Baierle, J. Valentini, C. Paniz, A. Moro, F.B. Junior, S. Garcia, Possible effects of blood copper on hematological parameters in elderly, J. Bras. Patol. Med. Lab. 46 (2010) 463-470.

[5] C.B. Netto, I.R. Siqueira, C. Fochesatto, L.V. Portela, M.D.P. Tavares, D.O. Souza, R. Giugliani, C.A. Gonçalves, S100 B content and SOD activity in amniotic fluid of pregnancies with Down syndrome, Clin. Biochem. 37 (2004) 134-137.

[6] N.E.L. Saris, E. Mervaala, H. Karppanen, J.A. Khawaja, A. Lewenstam, Magnesium, Clin. Chim. Acta. 294 (2000) 1-26.

[7] M.J. Dacey, Hypomagnesemic disorders, Crit. Care Clin. 17 (2001) 155-173.
[8] S. Bo, E. Pisu, Role of dietary magnesium in cardiovascular disease prevention, insulin sensitivity and diabetes, Curr. Opin. Lipidol. 19 (2008) 50-56.

[9] M.P. Rayman, Selenium and human health, Lancet 379 (2012) 1256-1268 d.

[10] K.J.C. Cruz, A.R.S. Oliveira, D.N. Marreiro, Antioxidant role of zinc in diabetes mellitus, World J. Diabetes 6 (2015) 333-337.

[11] A.H. Zargar, M.I. Bashir, S.R. Masoodi, B.A. Laway, A.I. Wani, A.R. Khan, F.A. Dar, Copper, zinc and magnesium levels in type-1 diabetes mellitus, Saudi Med. J. 23 (2002) 539-542.

[12] T.G. Kazi, H.I. Afridi, N. Kazi, M.K. Jamali, M.B. Arain, N. Jalbani, G.A. Kandhro, Copper chromium, manganese, iron, nickel, and zinc levels in biological samples of diabetes mellitus patients, Biol. Trace Elem. Res. 122 (2008) 1-18.

[13] P.M. Moraes, F.A. Santos, B. Cavecci, C.C.F. Padilha, J.C.S. Vieira, P.S. Roldan, P.D.M. Padilha, GFAAS determination of mercury in muscle samples of fish from Amazon, Brazil, Food Chem. 141 (2013) 2614-2617.

[14] A. Shevchenko, H. Tomas, J. Havlis, J.V. Olsen, M. Mann, In-gel digestion for mass spectrometric characterization of proteins and proteomes, Nat. Protoc. 1 (2006) 2856-2860

[15] G.Z. Li, J.P.C. Vissers, J.C. Silva, D. Golick, M.V. Gorenstein, S.J. Geromanos, Database searching and accounting of multiplexed precursor and product ion spectra from the data independent analysis of simple and complex peptide mixtures, Proteomics 9 (2009) 1696-1719.

[16] M.S. Cline, M. Smoot, E. Cerami, A. Kuchinsky, N. Landys, C. Workman, R. Christmas, I. Avila-Campilo, M. Creech, B. Gross, K. Hanspers, R. Isserlin, R. Kelley, S. Killcoyne, S. Lotia, S. Maere, J. Morris, K. Ono, V. Pavlovic, A.R. Pico, A Vailaya, P.L. Wang, A. Adler, B.R. Conklin, L. Hood, M. Kuiper, C. Sander, I. Schmulevich, B. Schwikowski, G.J. Warner, T. Ideker, G.D. Bader, Integration of biological networks and gene expression data using Cytoscape, Nat. Protoc. 2 (2007) 2366-2382.

[17] G. Wu, X. Feng, L. Stein, A human functional protein interaction network and its application to cancer data analysis, Genome Biol. 11 (2010) R53.

[18] F.A. Silva, B. Cavecci, W.A. Baldassini, P.M. Lima, P.M. Moraes, P.S. Roldan, C.C.F. Padilha, P.M. Padilha, Selenium fractionation from plasma, muscle and liver of Nile tilapia (Oreochromis niloticus), J. Food Meas. Charact. 7 (2013) 158-165.

[19] P.M. Lima, R.D.C.F. Neves, F.A. Dos Santos, C.A. Pérez, M.O.A. Da Silva, M.A.Z. Arruda, G.R. Castro, P.M. Padilha, Analytical approach to the metallomic of Nile tilapia (Oreochromis niloticus) liver tissue by SRXRF and FAAS after 2D-PAGE separation: preliminary results, Talanta 82 (2010) 1052-1056.

[20] H. Steinbrenner, H. Sies, Protection against reactive oxygen species by selenoproteins, Biochim. Biophys. Acta - Gen. Subj. 1790 (2009) 1478-1485.

[21] H. Steinbrenner, B. Speckmann, A. Pinto, H. Sies, High selenium intake and increased diabetes risk: experimental evidence for interplay between selenium and carbohydrate metabolism, J. Clin. Biochem. Nutr. 48 (2011) 40-45.

[22] M. Laclaustra, A. Navas-Acien, S. Stranges, J.M. Ordovas, E. Guallar, Serum selenium concentrations and diabetes in U.S. adults: national health and nutrition examination survey (NHANES) 2003-2004, Environ. Health Perspect. 117 (2009) 1409-1413.

[23] J. Bleys, A. Navas-Acien, E. Guallar, Serum selenium and diabetes in U.S. adults, Diabetes Care 30 (2007) 829-834.

[24] S. Czernichow, A. Couthouis, S. Bertrais, A.C. Vergnaud, L. Dauchet, P. Galan, S. Hercberg, Antioxidant supplementation does not affect fasting plasma glucose in the Supplementation with Antioxidant Vitamins and Minerals (SU.VI.MAX) study in France: association with dietary intake and plasma concentrations, Am. J. Clin. Nutr. 84 (2006) 395-399.

[25] B.J. Goldstein, M. Kalyankar, X. Wu, Redox paradox: insulin action is facilitated by insulin-stimulated reactive oxygen species with multiple potential signaling targets, Diabetes 54 (2005) 311-321.

[26] E. Alonso, J. Cervera, A. García-España, E. Bendala, V. Rubio, Oxidative inactivation of carbamoyl phosphate synthetase (ammonia). Mechanism and sites of oxidation, degradation of the oxidized enzyme, and inactivation by glycerol, EDTA, and thiol protecting agents, J. Biol Chem. 267 (1992) 4524-4532.

[27] S. Lee, W.H. Shen, A.W. Miller, L.C. Kuo, $\mathrm{Zn}^{2+}$ regulation of ornithine transcarbamoylase. I. Mechanism of action, J. Mol. Biol. 211 (1990) 255-269.

[28] L.C. Kuo, C. Caron, S. Lee, W. Herzberg, Zn2+ regulation of ornithine transcarbamoylase. II. Metal binding site, J. Mol. Biol. 211 (1990) 271-280.

[29] B.C. Yan, C. Gong, J. Song, T. Krausz, M. Tretiakova, E. Hyjek, H. Al-Ahmadie, V. Alves, S.Y. Xiao, R.A. Anders, J.A. Hart, Arginase-1: a new immunohistochemical marker of hepatocytes and hepatocellular neoplasms, Am. J. Surg. Pathol. 34 (2010) 1147-1154.

[30] C. Karlsson, H. Jornvall, J.O. Hoog, Sorbitol dehydrogenase: cDNA coding for the rat enzyme. Variations within the alcohol dehydrogenase family independent of quaternary structure and metal content, Eur. J. Biochem. 198 (1991) 761-765.

[31] K.L. Kvalnes-Krick, T.W. Traut, Cloning sequencing, and expression of a cDNA encoding beta-alanine synthase from rat liver, J. Biol. Chem. 268 (1993) 5686-5693.

[32] M.H. Lee, Z.H. Zhang, C.H. MacKinnon, J.E. Baldwin, N.P. Crouch, The C-terminal of rat 4-hydroxyphenylpyruvate dioxygenase is indispensable for enzyme activity, FEBS Lett. 393 (1996) 269-272.

[33] D. Phaneuf, Y. Labelle, D. Berube, K. Arden, W. Cavenee, R. Gagne, R.M. Tanguay, Cloning and expression of the cDNA encoding human fumarylacetoacetate hydrolase, the enzyme deficient in hereditary tyrosinemia: assignment of the gene to chromosome 15, Am. J. Hum. Genet 48 (1991) 525-535. 
[34] A. Lundby, A. Secher, K. Lage, N.B. Nordsborg, A. Dmytriyev, C. Lundby, J.V. Olsen, Quantitative maps of protein phosphorylation sites across 14 different rat organs and tissues, Nat. Commun. 3 (2012) 876.

[35] J.T. Rubino, K.J. Franz, Coordination chemistry of copper proteins: how nature handles a toxic cargo for essential function, J. Inorg. Biochem. 107 (2012) 129-143.

[36] E. Basha, H. O'Neill, E. Vierling, Small heat shock proteins and $\alpha$-crystallins: dynamic proteins with flexible functions, Trends Biochem. Sci. 37 (2012) $106-117$

[37] A. Mainz, B. Bardiaux, F. Kuppler, G. Multhaup, I.C. Felli, R. Pierattelli, B. Reif, Structural and mechanistic implications of metal binding in the small heat-shock protein $\alpha$ B-crystallin, J. Biol. Chem. 287 (2012) 1128-1138.

[38] Y.H. Han, S.J. Hong, H.K. Cheong, Y.J. Chung, Crystal structures of $26 \mathrm{kDa}$ Clonorchis sinensis glutathione S-transferase reveal zinc binding and putative metal binding, Biochem. Biophys. Res. Commun. 438 (2013) 457-461.
[39] A. Gururaj, C.J. Barnes, R.K. Vadlamudi, K.R. Kumar, Regulation of phosphoglucomutase 1 phosphorylation and activity by a signaling kinase, Oncogene 23 (2004) 8118-8127.

[40] L. Lebioda, B. Stec, J.M. Brewer, E. Tykarska, Inhibition of enolase: the crystal structures of enolase-calcium(2+)-2-phosphoglycerate and enolase-zinc(2+)-phosphoglycolate complexes at 2.2-.ANG. resolution, Biochemistry 30 (1991) 2823-2827.

[41] L. Lebioda, B. Stec, Mechanism of enolase: the crystal structure of enolase-Mg2(+)-2-phosphoglycerate/phosphoenolpyruvate complex at 2.2-A resolution, Biochemistry 30 (1991) 2817-2822.

[42] M.R. el-Maghrabi, A.J. Lange, L. Kummel, S.J. Pilkis, The rat fructose-1, 6-bisphosphatase gene. Structure and regulation of expression, J. Biol. Chem. 266 (1991) 2115-2120. 